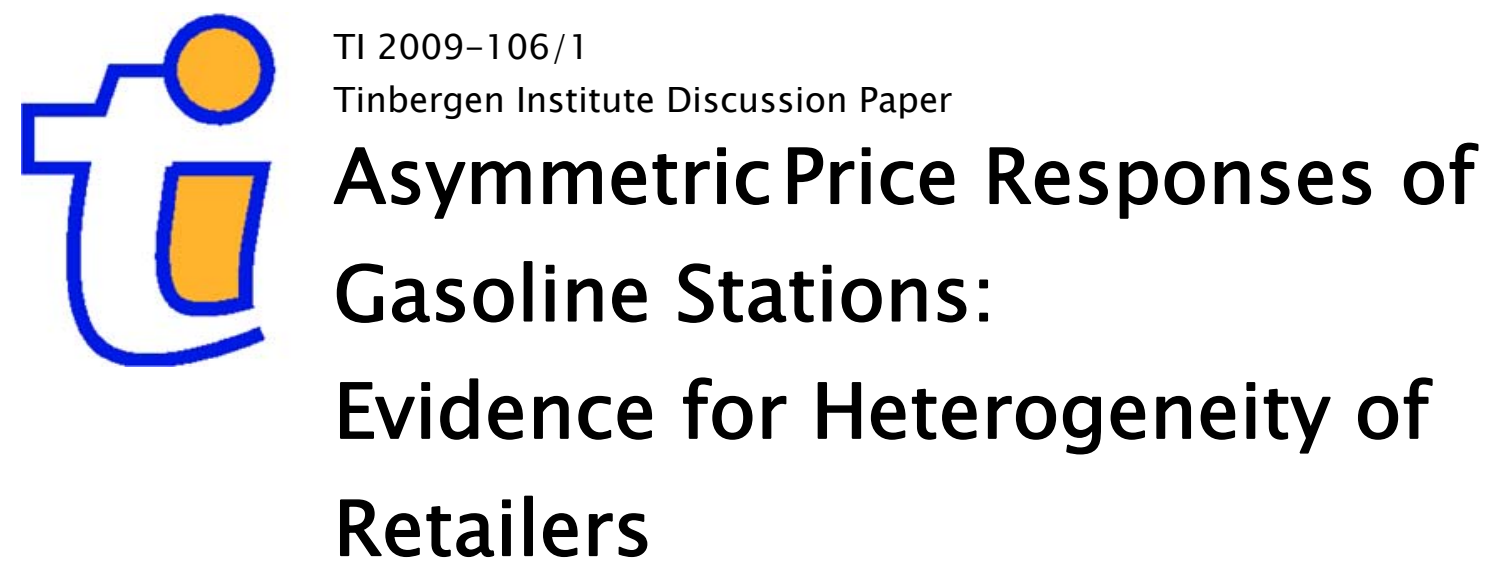

Riemer P. Faber 


\section{Tinbergen Institute}

The Tinbergen Institute is the institute for economic research of the Erasmus Universiteit Rotterdam, Universiteit van Amsterdam, and Vrije Universiteit Amsterdam.

Tinbergen Institute Amsterdam

Roetersstraat 31

1018 WB Amsterdam

The Netherlands

Tel.: +31(0)205513500

Fax: $+31(0) 205513555$

Tinbergen Institute Rotterdam

Burg. Oudlaan 50

3062 PA Rotterdam

The Netherlands

Tel.: + $31(0) 104088900$

Fax: $+31(0) 104089031$

Most TI discussion papers can be downloaded at http://www.tinbergen.nl. 


\title{
ASYMMETRIC PRICE RESPONSES OF GASOLINE STATIONS: EVIDENCE FOR HETEROGENEITY OF RETAILERS ${ }^{1}$
}

\author{
Riemer P. Faber ${ }^{2}$
}

November 10, 2009

\begin{abstract}
This paper studies asymmetric price responses of individual firms, via daily retail prices of almost all gasoline stations in the Netherlands and suggested prices of the five largest oil companies over more than two years. I find that $38 \%$ of the stations respond asymmetrically to changes in the spot market price. Hence, asymmetric pricing is not a feature of the market as a whole, but of individual firms. For asymmetrically pricing stations, the asymmetry is substantial directly after a change but disappears after one or two days. I study station-specific characteristics and conclude that asymmetric pricing seems to be a phenomenon that is randomly distributed across stations. I also find that none of the five largest oil companies adjust their suggested prices asymmetrically.
\end{abstract}

Key Words: price setting, asymmetric price responses, gasoline markets

JEL code: D40, E31, L11, L81

\footnotetext{
${ }^{1}$ I thank Maarten Janssen, Nick Vikander, and seminar participants at the Tinbergen Institute for valuable comments. I thank Rikkert Nachtegaal for help with the data.

${ }^{2}$ Department of Economics, Erasmus University Rotterdam and Tinbergen Institute. P.O. Box 1738, 3000 DR Rotterdam, The Netherlands. E-mail: faber@ese.eur.nl
} 


\section{Introduction}

Asymmetric price responses occur when prices rise more rapidly after an increase in costs than they decline after a decrease in costs (see Peltzman (2000)). Many policy makers, consumers, and consumer organizations are suspicious that this pricing behavior is common in many markets, in particular in agricultural and gasoline retail markets. ${ }^{1}$ This paper studies price responses of gasoline stations and oil companies in the Netherlands and focuses on the price setting and characteristics of individual firms.

There already exists a substantial literature on asymmetric price responses. Frey and Manera (2007) provide a survey of the empirical literature. Some of these papers focus on gasoline retail markets. For example, Borenstein, Cameron, and Gilbert (1997) study the US gasoline market and find that semimonthly aggregated retail prices respond asymmetrically to wholesale price changes. Studies that use weekly data of individual gasoline stations are Lewis (2005) (420 stations), Verlinda (2008) (approximately 90 stations), Balmaceda and Soruco (2008) (44 stations), and Hosken, McMillan, and Taylor (2008) (272 stations). The first three studies report evidence at the market level for asymmetric retail price responses to spot market price changes. ${ }^{2}$ Deltas (2008) investigates asymmetry via monthly US state retail prices, Lewis and Noel (2009) use daily city retail prices, and Radchenko (2005) uses weekly national retail prices. These studies also find evidence of asymmetric price responses. For the Netherlands, Bettendorf, Van der Geest, and Varkevisser (2003) and Bettendorf, Van der Geest, and Kuper (2009) study the daily suggested price of one oil company and find some evidence of asymmetric price responses to changes in the spot market price.

Asymmetric price responses are not consistent with standard models of perfect competition or monopoly. Most theoretical studies mark tacit collusion and a low search intensity as possible causes

\footnotetext{
${ }^{1}$ See, for example, European Commission, "Food prices in Europe" (December 9, 2008), De Consumentenbond, "Supers woekeren met groente en fruit" (De Consumentengids, November 2008, pp. 32-33), De Consumentenbond, "Pompprijs volgt wereldmarkt" (De Consumentengids, April 2009, pp. 10-11), and De Telegraaf, "Mythes over benzineprijs zorgen voor veel onrust" (September 19, 2008).

${ }^{2}$ Noel (2009) uses twice-daily prices of 22 gasoline stations and finds asymmetric pricing at the market level. However, there also exist Edgeworth cycles in this market. He shows that these cycles have an impact on asymmetric pricing.
} 
for asymmetry. ${ }^{3}$ To empirically distinguish between these two causes is difficult. Verlinda (2008) and Deltas (2008) conclude that market power can be an important factor for explaining asymmetry. ${ }^{4}$ However, market power can explain asymmetry via both tacit collusion (see Verlinda (2008)) and a low search intensity (see Deltas (2008)). Radchenko (2005) explains asymmetry via volatility of the input price (see also Peltzman (2000)) and finds that tacit collusion is a likely explanation.

Almost all studies of asymmetric price adjustments use (1) price data that have a lower frequency than the frequency of price decisions or input cost changes (they use, for example, weekly data) or (2) data that are aggregated over large geographic areas (for example, an average national retail price). ${ }^{5}$ These data limitations possibly lead to biased results (see also Geweke (2004)). First, to investigate asymmetric price responses it is important to have price data with a similar frequency as the highest frequency at which price decisions are taken or input costs change. Only in this case will the analysis include all (possible) price adjustments. ${ }^{6}$ Second, it is important to have data on price decisions of individual gasoline stations since an individual gasoline station, and not the market as a whole, chooses to adjust prices asymmetrically or not. It may very well be that not all gasoline stations have the same pricing strategy, for example, because they do not operate under the same conditions (competition, ownership structure, location, etc.). Moreover, even if all gasoline stations respond

\footnotetext{
${ }^{3}$ See Johnson (2002), Lewis (2005), Cabral and Fishman (2008), Deltas (2008), Yang and Ye (2008), and Tappata (2009) for an explanation using search costs. See Rotemberg and Saloner (1986), Haltiwanger and Harington (1991), Borenstein and Shepard (1996), Borenstein, Cameron, and Gilbert (1997), Balke, Brown, and Yücel (1998), and Verlinda (2008) for an explanation using tacit collusion.

${ }^{4}$ Verlinda (2008) links characteristics of gasoline stations to the existence of asymmetric pricing. He shows that brand identity, proximity to rival gasoline stations, and local market features and demographics all have an impact. Deltas (2008) concludes that US states with higher average margins have a higher degree of asymmetry. However, Balmaceda and Soruco (2008) find that a group of branded stations and a group of stations with a high margin have the same degree of asymmetry as respectively a group of unbranded stations and a group of stations with a low margin.

${ }^{5}$ One exception is Balmaceda and Soruco (2008), who use weekly retail and spot market price data from Chile. Because of institutional factors gasoline stations and the state-owned oil company adjust prices only once a week.

${ }^{6}$ Several papers report biases due to this type of data limitation. Bachmeier and Griffin (2003) use weekly and daily spot market data and show that their conclusions depend on the frequency of the data used. Noel (2009) shows that there may exist, next to asymmetric pricing, other irregularities in a market that have an impact on asymmetric pricing, but that cannot be observed in a low frequency data set. For example, the Edgeworth cycles that he finds take approximately one week. Eckert and West (2004) have a daily data set for a region in Canada and conclude that a subset of weekly observations is not sufficient for answering their research questions and can even be misleading. Moreover, Bettendorf, Van der Geest, and Varkevisser (2003) have daily data on a suggested price and estimate a separate model for each day of the week. For some days they find asymmetric prices responses, for others not. These results show that data selection may influence conclusions regarding asymmetric price responses.
} 
asymmetrically, it is possible that they do not all respond similarly to cost changes (for example, the speed of adjustment differs). For these reasons aggregated price data may have a summation bias.

This paper studies the daily pricing behavior of almost all gasoline stations and oil companies in the Netherlands over more than two years. Oil companies issue national suggested prices for gasoline, but retail prices are decided at the station level (see Faber and Janssen (2008)). I disentangle three main questions: (1) To what degree do oil companies respond asymmetrically to changes in the spot market price? (2) To what degree do gasoline stations respond asymmetrically to changes in the spot market price and are there important differences between stations? (3) What kind of gasoline stations respond asymmetrically? The first two questions study whether there exists heterogeneity in the pricing behavior of firms and the third question studies this heterogeneity.

To answer these questions, I use a panel data set consisting of daily gasoline prices of about 3,600 gasoline stations and daily suggested prices of the five largest oil companies over the period May 30 2006 - July 20 2008. By using this daily data set I can prevent possible estimation biases, since oil companies and almost all gasoline stations choose their prices on a daily basis and input costs for gasoline (the spot market price) also change daily. Moreover, I have data on the characteristics of individual gasoline stations, so it is possible to look into the characteristics of stations that price asymmetrically.

I find that none of the oil companies adjust their suggested prices asymmetrically to changes in the spot market price. I also find that there are significant differences between stations. Many stations do not price asymmetrically, but $38 \%$ of the stations do. Directly after a cost shock, the extent of asymmetry is substantial for these stations. One day after a 1 cent increase in the spot market price, the price at stations that adjust prices asymmetrically rises on average by 0.346 cent. One day after a 1 cent decrease in the spot market price, the price at these stations decreases by 0.153 cent on average. So after one day there is on average an asymmetry of 0.193 cent. However, for most stations that adjust prices asymmetrically, the asymmetry only lasts a short period of time. For asymmetrically pricing stations it takes on average about 10 days before the retail price fully reflects the change in the 
spot market price. The asymmetric part of this transmission process for most stations is directly after the cost shock and lasts only 1 or 2 days.

It is not clear why some gasoline stations set prices asymmetrically and others do not. I look at 35 (sometimes overlapping) station-specific characteristics that I associate with tacit collusion and/or search intensity (such as price level, ownership structure, and the number of close competitors). I do not find a clear pattern in the characteristics of asymmetrically pricing stations. Although I cannot find a clear explanation for asymmetry, this study implies that if there is an explanation, it should be found at the individual level, since some stations do and others do not adjust prices asymmetrically.

The contribution of this study to the already large literature on asymmetric price adjustments is that it gives insight in the pricing behavior of individual firms on a daily basis. This study shows that asymmetry is not a feature of the market as a whole, but of individual firms. For that reason the extent of asymmetry at the individual level is higher than the extent at the market level. I measure how many retailers adjust prices asymmetrically and study the differences between retailers. Up until now, there is very little literature on asymmetric pricing by individual retailers compared to the literature on asymmetry at the market level. Moreover, few empirical papers study characteristics of asymmetrically pricing retailers. Finally, because of the detailed data set I can rule out a possible bias caused by aggregation over individuals and minimize a possible bias caused by aggregation over time. The conclusions that I draw in this paper would not be possible without this detailed data set. For example, the asymmetric part of the transmission process for most stations lasts only one or two days and takes place directly after a cost shock. So with weekly data the asymmetric part of the transmission process would have been unobserved.

This paper is organized as follows. Section 2 describes the gasoline retail market and the data set. Each of the next three sections considers one of the three research questions. Section 3 studies whether oil companies adjust their suggested prices asymmetrically. Section 4 studies whether gasoline stations adjust their retail prices asymmetrically. Section 5 explores the characteristics of asymmetrically pricing stations. Section 6 concludes. 


\section{A description of the gasoline retail market and the data set}

\section{$\underline{\text { The gasoline retail market }}^{7}$}

There are around 4,300 gasoline stations in the Netherlands with the five largest oil companies (BP, Esso, Shell, Total, and Texaco) having a total market share of around $70 \%$ (measured as the total number of stations using the brand of these five companies divided by the total number of stations). Roughly speaking there are three types of ownership models: some stations (including almost all the larger stations along the highways) are company-owned and company-operated (coco), other stations are company-owned and dealer-operated (codo), and the remaining stations are dealer-owned and dealer-operated (dodo). Coco stations are not free to set their own gasoline prices: these prices are set at the central company level. The dealers of a codo station rent the stations from the oil company, participate in the company's sales and loyalty programs, but are free to set their own prices. Finally, dodo stations operate most independently from the larger oil companies, although even these stations have to buy the gasoline they sell from the oil company. Approximately $60 \%$ of the stations are dealerowned. Rough estimates indicate that around $80 \%$ of the stations are dealer-operated.

There is a close relation between the input prices for gasoline and the prices on the international market. Although the large oil companies cover the complete production chain from extracting oil to selling gasoline, the Dutch gasoline sales divisions mainly buy their gasoline at the AmsterdamRotterdam-Antwerp (ARA) spot market which supplies large parts of western Europe. A price for this spot market is published once a day. Shell (the largest oil company) claims that even if the Dutch sales division buys gasoline from a production division, it uses this spot market price as internal price. ${ }^{8}$

The larger oil companies have suggested prices that they determine on a daily basis. Shell has published detailed descriptions on how they calculate their suggested price (see, e.g., Shell (2001) and the Shell website). They claim that every morning they take the spot market price of the previous day (which is the most recent price available) and add different taxes and margins (for transport, sales costs, etc.) to come up with a price they think gasoline stations should charge for their gasoline. If this

\footnotetext{
${ }^{7}$ Unless mentioned otherwise, the source of the data in this section is BOVAG (2006).

${ }^{8}$ www.shell.nl
} 
price is different from the current price, a pricing committee meets to determine whether they change the suggested price and by how much. If the committee decides to change the price, the oil company communicates the new price (which is valid from the next day onward) via fax and e-mail to all dealers in the evening. Dealers can then update their prices the next morning. If they indeed follow this decision process, the delay between changes in the spot market price and prices at stations is exactly two days.

\section{The data set}

Retail gasoline prices are published daily on the website of Athlon Car Lease. ${ }^{9}$ This company leases cars to other firms including a so-called "fuel card". If the driver fills up his car with gasoline, he shows the card to the station and the retailer electronically sends the bill with price and quantity information to the lease company at the same time. As a result, Athlon Car Lease obtains gasoline price notations from 120,000 drivers, who fill up on average twice a week, from all over the Netherlands. Athlon Car Lease puts the data on gasoline prices on its website and I have downloaded the data daily over the period May 302006 - July 20 2008. As indicated in the previous subsection, there are approximately 4,300 gasoline stations in the Netherlands, of which the data set includes about 3,600 . Stations that the data set does not include seem to be mostly smaller and non-active stations randomly distributed over the country. The amount of stations I report throughout the paper is not exactly equal to the number of physical stations. For some gasoline stations in the data set, the name changes during the sample period and I do not merge the series of these stations. Data are available for seven different kinds of gasoline: Euro95, Diesel, Super, Super Plus, Special Euro95, Special Diesel, and untaxed Diesel. I focus on Euro95. The whole data set contains approximately 6,000 unique station-gasoline type-price quotations per day. ${ }^{10}$ For each station-gasoline type combination I have a maximum of one price quotation per day. Since less busy stations have a lower probability of being visited by a driver of a car leased from Athlon Car Lease, the data set contains

\footnotetext{
${ }^{9}$ www.athloncarlease.nl

${ }^{10}$ Only a couple of observations in the data set are suspicious. There seem to be a few cases where a certain type of gasoline is reported as another kind of gasoline. I deleted these quotations.
} 
more quotations of busier stations. This does not have an impact on the analysis, however, as there is no indication that the pricing decisions of larger gasoline stations differs significantly from that of smaller ones (after correction for ownership structure). Finally, drivers do not have to pay for the gasoline (because the firm that employs the driver does). So these users do not avoid more expensive stations. Casual observation shows that they also do not avoid cheaper stations.

I matched individual stations in the data set to lists of station-specific characteristics, namely owner and brand of a station and whether a station is located along a highway. ${ }^{11}$ I do not have data on the operator of a station, but I do know the ownership structure. As a consequence, I am able to filter out the stations where an oil company decides on the price. I also matched each station to data on the area in which the station is located (income per capita, population, number of cars, number of people older than 60 , number of immigrants (all per 4 digit zip code), and unemployment (per municipality)). ${ }^{12}$

During the sample period I downloaded the suggested prices from the website of United Consumers. This website contains daily suggested prices of the five largest oil companies for eleven different types of gasoline (some types are brand specific). ${ }^{13}$ The spot market notation I use is the daily Platt's Barges FOB Rotterdam High (series for Euro95: Premium Gasoline 10 PPM). Shell uses the same notation for calculating the suggested price (Shell (2001)).

The websites of the European Central Bank and the Dutch Ministry of Finance provided respectively the dollar-euro exchange rate and data on taxes. I converted all gasoline prices to prices per liter (excluding taxes) in euros.

\footnotetext{
${ }^{11}$ I obtained lists with the ownership structure and brand of a station from Catalist (a company collecting data on gasoline stations) and a list with highway stations from the Dutch Ministry of Finance. It may be that stations change their brand or ownership structure during the sample period. As I do not have information on this, I assume that stations do not change their brand and ownership structure.

${ }^{12}$ The source of these data is the website of Statistics Netherlands.

${ }^{13}$ The suggested price of Shell increases 125 times and decreases 122 times during the sample period. For other brands these numbers are similar.
} 


\section{Do oil companies respond asymmetrically?}

In this section I study if oil companies adjust their suggested prices asymmetrically to changes in the gasoline spot market price. Augmented Dickey-Fuller unit root tests indicate that the spot market price and suggested prices of the five largest oil companies are integrated of order 1 . Therefore I estimate asymmetric error correction models to take into account possible cointegration between the suggested price and the spot market price. ${ }^{14}$ The long-run relationship between the spot market price and the suggested price for each oil company $i$ is:

$\operatorname{Sug}_{i, t}=\alpha_{i}^{*} \operatorname{Spot}_{t-2}+c_{i}^{*}+\tau_{i}^{*} \operatorname{Time}_{t}+\lambda_{i}^{*} \operatorname{Mix}_{t}+\varepsilon_{i, t}^{*}$

where $\operatorname{Sug}_{i, t}$ is the suggested price of oil company $i$ for one liter of gasoline at day $t, \operatorname{Spot}_{t-2}$ is the gasoline spot market price at day $t-2$, and $c_{i}^{*}$ is a constant that reflects the average gross margin for the oil company and gasoline station. Time $e_{t}$ is a time trend that captures a possible inflationary increase in the margin, Mix $x_{t}$ is a dummy variable which is 1 after January $1^{\text {st }} 2007$ (law requires oil companies to add biofuels from that date onward), and $\varepsilon_{i, t}^{*}$ is an error term. All prices are in euro per liter and exclude excise duty and VAT. I use the two-day lagged spot market price for gasoline, since this is the relevant input price for the suggested price (see Section 2). ${ }^{15}$

I choose a linear relationship instead of a log specification because the data show that the absolute difference between the suggested price and spot market price is stable and independent of the level of the spot market price (see also Borenstein, Cameron, and Gilbert (1997)). Taxes do not differ substantially over the estimation period and I do not consider their impact. I do not make a distinction between changes in the exchange rate and changes in the spot market price in dollars.

If the residuals of Equation 1 are stationary, a cointegrating relation exists. In that case I can superconsistently estimate the coefficients in Equation 1 and define a short-run relation between the variables. First, I specify for each oil company a symmetric relation between the suggested price and the spot market price:

\footnotetext{
${ }^{14}$ These are the standard models in this literature, see, e.g., Bachmeier and Griffin (2003) and Frey and Manera (2007).

${ }^{15}$ The spot market price has the highest correlation with the suggested price if I use a two-day lag.
} 
$\Delta \operatorname{Sug}_{i, t}=\alpha_{i, 1} \Delta \operatorname{Spot}_{t-1}+\sum_{j=0}^{k} \alpha_{i, 2+j} \Delta \operatorname{Spot}_{t-2-j}+\sum_{j=1}^{l} \beta_{i, j} \Delta \operatorname{Sug}_{i, t-j}+\gamma_{i} \varepsilon_{i, t-1}^{*}+\mu_{i, t}$

where $\mu_{i, t}$ is an error term. ${ }^{16}$ In this equation I include the one-day lagged change in the spot market price as well. The two-day lagged spot market price is the relevant price for the suggested price (see Section 2 and Equation 1). This price is the most recent quotation available at the moment the pricing decision is made. However, at the moment that an oil company decides on its suggested price for day $t$ (the morning/afternoon of $t-1$ ), it can take into account the movements of the spot market price it perceives on $t-1$ (or it can look at prices of related products (e.g., crude oil) for which real-time price data are available). I use the change in the one-day lagged spot market price as a proxy for the new information that became available since the most recent daily spot market price was published.

Second, I specify an asymmetric relation between the suggested price of an oil company and the spot market price: ${ }^{17}$

$$
\begin{aligned}
\Delta \operatorname{Sug}_{i, t} & =\alpha_{i, 1}^{+} \Delta \operatorname{Spot}_{t-1}^{+}+\alpha_{i, 1}^{-} \Delta \operatorname{Spot}_{t-1}^{-}+\sum_{j=0}^{v} \alpha_{i, 2+j}^{+} \Delta \operatorname{Spot}_{t-2-j}^{+}+\sum_{j=0}^{w} \alpha_{i, 2+j}^{-} \Delta \operatorname{Spot}_{t-2-j}^{-} \\
& +\sum_{j=1}^{\chi} \beta_{i, j}^{+} \Delta \operatorname{Sug}_{i, t-j}^{+}+\sum_{j=1}^{y} \beta_{i, j}^{-} \Delta S u g_{i, t-j}^{-}+\gamma_{i}^{+} \varepsilon_{i, t-1}^{*+}+\gamma_{i}^{-} \varepsilon_{i, t-1}^{*_{-}}+\mu_{i, t}
\end{aligned}
$$

where for each variable $z: \Delta z^{+}=\max \{\Delta z, 0\}$ and $\Delta z^{-}=\min \{\Delta z, 0\}$. And where $\varepsilon_{i, t-1}^{*_{+}}=\max \left\{\varepsilon_{i, t-1}^{*}, 0\right\}$ and $\varepsilon_{i, t-1}^{*_{-}}=\min \left\{\varepsilon_{i, t-1}^{*}, 0\right\}$. A plus (minus) as superscript to a coefficient indicates that the coefficient belongs to an increasing (decreasing) variable. Besides price asymmetry via the impact of current and lagged changes in the spot market price and lagged changes in the suggested price, it is also possible that there is asymmetry in the speed of adjustment to the equilibrium suggested price. If $\left|\gamma_{i}^{-}\right|>\left|\gamma_{i}^{+}\right|$, then the suggested price returns more slowly to its equilibrium value if the suggested price exceeds its equilibrium value.

Inspection of the data shows that the five largest oil companies never change suggested prices on Sundays and rarely on Mondays. This is possibly the case because the suggested prices for these days

\footnotetext{
${ }^{16}$ Equation 1 and 2 can be rewritten into a standard ARDL $(k+1, l+1)$ model.

${ }^{17}$ A long-run asymmetric relation between the spot market price and suggested price cannot exist. If in the long run the pass-through of increases in the spot market price is stronger than the pass-through of decreases, this would imply that margins would increase infinitely over time.
} 
should be decided on Saturdays and Sundays and these are not working days. Since I would like to explain suggested prices by the spot market price and not by working schedules, I exclude from my sample the days for which the suggested price should be decided during weekends and official national holidays (547 out of 783 days are left). So differenced variables reflect differences between days on which oil companies decide on the suggested price.

I estimate a separate specification for each oil company. I use the Engle-Granger two-step estimation procedure and estimate all equations by OLS. To interpret the estimation results and test for asymmetric price responses, I calculate cumulative adjustment functions (see Borenstein, Cameron, and Gilbert (1997)). These functions measure the cumulative change in the suggested prices after a 1 cent increase and a 1 cent decrease in the spot market price. I compute the cumulative change in the suggested prices up to 25 days after the shocks. The difference between the cumulative change in the suggested price after a 1 cent increase and a 1 cent decrease in the spot market price reflects the degree of asymmetry at a certain point in time.

First I estimate Equation 1 for each oil company. Then I take the residuals and estimate Equation 3 for each oil company. I choose the lag lengths $(v, w, x$, and $y)$ by using the Schwarz information criterion and this procedure results in lag lengths of zero for all variables and brands. ${ }^{18}$ I use White heteroskedasticity-consistent standard errors. The residual-based test for cointegration rejects the null of no cointegration for all five oil companies. The estimated coefficient for the long-run impact of the spot market price is close to 1 for all five brands. ${ }^{19}$ Thus, in the long run there is a full pass-through of changes in the spot market price into the suggested price. ${ }^{20}$

Figure 1 shows the cumulative adjustment functions of the suggested prices after a 1 cent positive and a 1 cent negative change in the spot market price. The figure also reports the difference between the cumulative adjustments and its $95 \%$ confidence interval. ${ }^{21}$ I first discuss the cumulative adjustment of

\footnotetext{
${ }^{18}$ Only for Brand B the Schwarz information criterion prefers $w=1$, but differences are minor and for comparison with the other brands I report results for $w=0$.

${ }^{19}$ The values of the estimated coefficients (and their standard errors) are $1.006(0.006), 1.009(0.005), 1.003$ (0.005), 0.998 (0.006), and $0.983(0.005)$.

${ }^{20}$ Throughout the paper I do not report other parameter estimates to save space (I only report the major variable in the long-run relation), but instead I present the estimation results via cumulative adjustment functions. Parameter estimates are (like all other omitted results) available upon request.

${ }^{21}$ I use the delta method to derive the standard errors.
} 
Brand A (upper left corner of the figure). It shows that the difference is positive in the first few days after the change in the spot market price, but the difference is never significantly different from 0 ( 0 is always in the $95 \%$ percent confidence interval). For example, two days after an increase, the passthrough in the suggested price is 0.581 cent. However, two days after a decrease, the pass-through is only 0.485 cent. No difference remains after about four days. After approximately seven days the oil company has fully absorbed the shock in its suggested price. The cumulative adjustment functions for the other oil companies are similar. For all five oil companies there is some asymmetry, but this is never statistically significant.

\section{Do gasoline stations respond asymmetrically?}

In this section I take up the question whether gasoline stations adjust their retail prices asymmetrically to changes in the spot market price. I define $P_{i, t}$ as the retail price of station $i$ for one liter of gasoline at day $t$ (in euro per liter, excluding excise duty and VAT). Since I already modeled the relation between the spot market price and suggested price in Section 3, I obtain the appropriate equations for the relation between the spot market price and retail price by taking Equation 1, 2, and 3 and simply replace $\operatorname{Sug}_{i, t}$ by $P_{i, t}$ in these equations (I refer to these equations as respectively 1', 2', and 3'). ${ }^{22}$ In Equation 1', 2', and 3', the subscript i refers to gasoline station $i$.

In contrast to oil companies, gasoline stations are open on weekends and during holidays and thus have the opportunity to change their price on these days. For that reason I include all days in the sample. I estimate the relationship when all gasoline stations are pooled (to measure asymmetry at the market level) and also for each individual gasoline station (to measure asymmetry at the firm level). To interpret the estimation results I calculate cumulative adjustment functions to measure the cumulative change in the retail prices up to 25 days after a 1 cent increase and a 1 cent decrease in the spot market price.

\footnotetext{
${ }^{22}$ The one-day lagged spot market price is not a proxy for new information in this specification since gasoline stations know this price at the moment that they decide on their retail price. The change in the current spot market price has no explanatory power for the change in the retail price. I take the two-day lagged spot market price as the long-run equilibrium price. The retail price has the highest correlation with the spot market price if I use a two-day lag. Moreover, the two-day lagged spot market price is the basis for the suggested price (see Section 2). Faber and Janssen (2008) show that many retailers use the suggested price for setting their price.
} 
Figure 1 Cumulative adjustments of the suggested prices (after spot market price change)
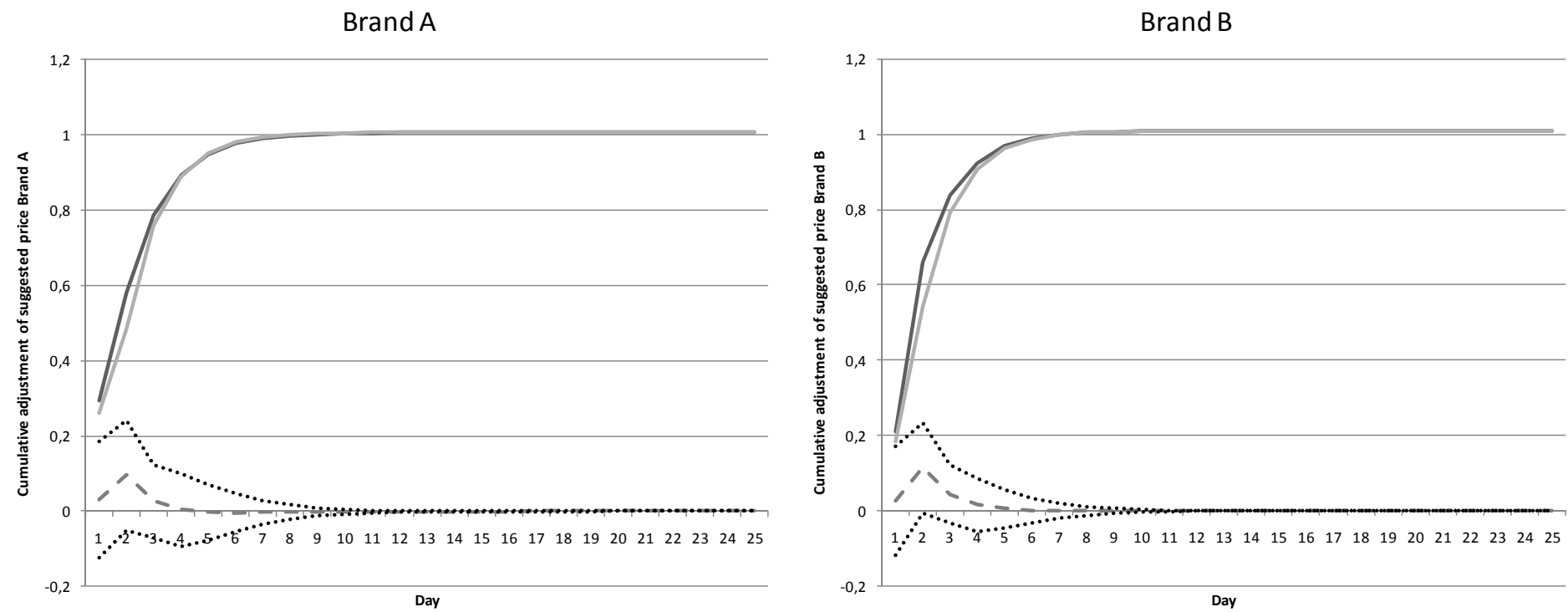

Brand C
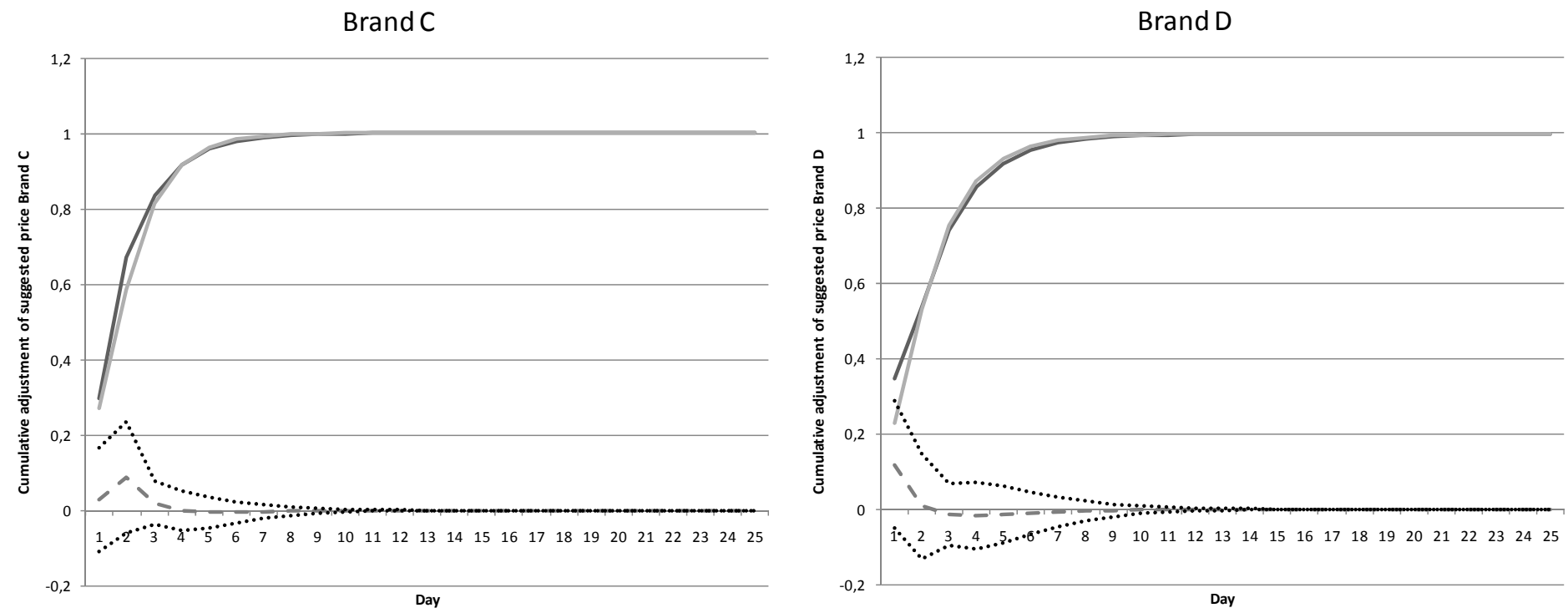

Brand $\mathrm{E}$

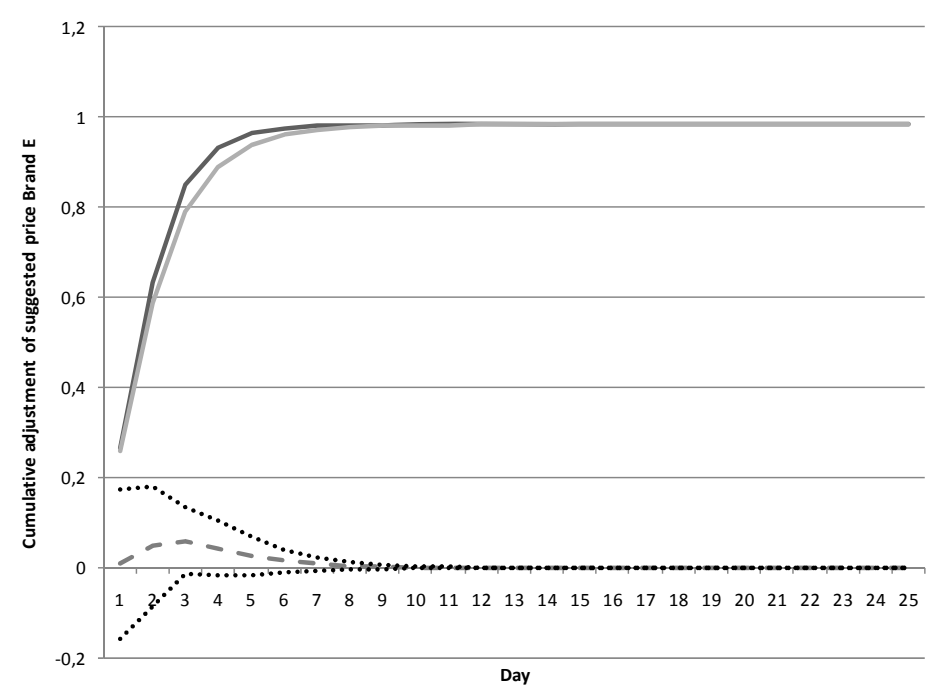

—plus 1

- |minus 1|

- - difference

...... $95 \%$ confidence 


\section{$\underline{\text { All stations pooled }}$}

First, I estimate the pooled equation. This implies that $\psi_{i}=\psi$ for each coefficient and the error term in Equations 1', 2', and 3'. I use Driscoll-Kraay standard errors that are robust to heteroskedasticity, serial correlation, and cross-sectional correlation (see Driscoll and Kraay (1998) and Hoechle (2007)). Augmented Dickey-Fuller Fisher panel unit root tests (Maddala and Wu (1999), Choi (2001)) indicate that retail prices are, like the spot market price, integrated of order one. The panel cointegration test of Kao (1999) reveals homogeneous cointegration between retail prices and the spot market price. The estimated coefficient for the long-run impact of the spot market price is 0.993 (standard error equals 0.007). To further interpret the results, I look at the cumulative adjustment function.

Figure 2 shows the cumulative adjustment function for $v=w=x=y=1$ (for other specifications the results are similar). ${ }^{23}$ There is significant asymmetry at the market level. However, the extent of asymmetry is moderate and the asymmetry lasts for a short time. The difference in the cumulative change in the retail price after a 1 cent increase and a 1 cent decrease in the spot market price is significantly different from 0 on the first day after the shock (the absolute difference is 0.120 cent). On day 2 there is a still a difference ( 0.062 cent), but this is not significantly different from 0 . After these two days the difference is negligible. After 16 days, retail prices have adsorbed more than $97.5 \%$ of both the positive and negative shock. ${ }^{24}$ In the next paragraphs I study asymmetry at the firm level.

\footnotetext{
${ }^{23}$ The specification that I present uses in total 3,658 stations and 1,052,741 observations.

${ }^{24}$ The sum of the difference between the positive and negative cumulative adjustment equals 0.199 cent after 25 days. So if a consumer buys 1 liter per day for 25 consecutive days after the shock, the consumer paid in total 0.199 cent more after a 1 cent increase in the spot market price than what the consumer would have saved after a 1 cent decrease. Per day gasoline stations sell in total 14,3 million liters of Euro95 (data for 2004, BOVAG (2006)). This implies that all consumers together pay 28,423 euros more after a 1 cent increase in the spot market price than they save after an equal decrease.
} 
Figure 2 Cumulative adjustment of retail prices (after spot market price change, pooled estimation)

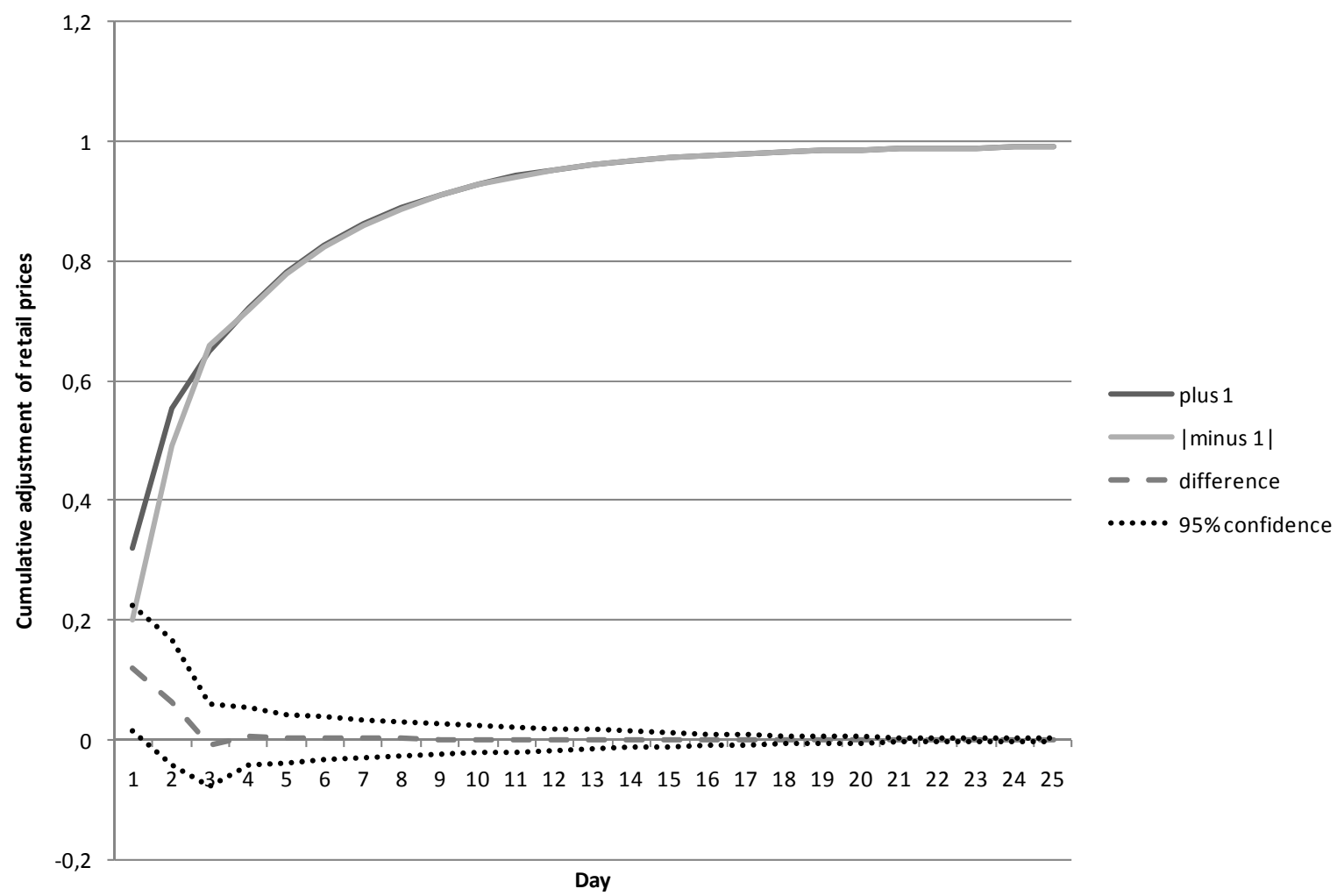

\section{$\underline{\text { Individual stations }}$}

I estimate Equation 1' and 3' for 2,365 gasoline stations. ${ }^{25}$ I choose a maximum value for $v, w, x$, and $y$ of 3 and select the lag length via the Schwarz information criterion. ${ }^{26}$ The mean of the estimated longrun impact of the spot market price on the retail price is 0.988 (standard deviation equals 0.045 ). Based on these and the other estimated coefficients, I calculate a cumulative adjustment function for each station.

\footnotetext{
${ }^{25}$ The sample contains 4,004 stations. For 2,549 stations there is enough data to estimate both Equation 1' and 3'. I exclude 7 stations because the residual-based test for cointegration could not reject the null of no cointegration in Equation 1' (all price series of the estimated stations are integrated of order 1). Furthermore, I exclude 49 stations because the estimated $\gamma_{i}^{+}$or $\gamma_{i}^{-}$in Equation 3' is not between -2 and 0 (indicating that for these stations the retail price does not return to its equilibrium value) and 128 stations for which 20 or fewer observations that differ from 0 are available for estimating one of the parameters in Equation 3' (more restrictive conditions do not change results much). There are 2,365 stations left. Of these 2,365 stations, I correct the standard errors for 1,148 stations for heteroskedasticity and for 910 stations for heteroskedasticity and serial correlation.

${ }^{26}$ If I use a higher maximum lag length I can estimate the equation for fewer stations and in practice only a limited number of stations use more than 1 lag.
} 
First, I calculate the percentage of gasoline stations that adjust prices asymmetrically. For each gasoline station I calculate the number of days for which the difference between the cumulative price change after a positive shock and after a negative shock is positive and significantly different from 0 at the $5 \%$ significance level. When this number of days is one or more, I define a station as responding asymmetrically. Most gasoline stations do not price asymmetrically. However, a substantial part of the gasoline stations do. Table 1 shows that $38 \%$ of the gasoline stations respond asymmetrically. ${ }^{27}$ The table also shows the total length of the asymmetric part of the transmission process. This total length differs between stations, although for most stations that adjust prices asymmetrically the asymmetry exists for only 1 or 2 days. There is hardly any station for which a positive shock leads to a significantly larger cumulative price adjustment than a negative shock for 5 days or more.

Second, I study on which days the transmission processes are asymmetric. Does asymmetry arise directly after the shock or only after a couple of days? For each day I calculate the number of gasoline stations for which the difference between the cumulative price change after a positive shock and a negative shock is positive and significantly different from 0 . Figure 3 shows the results. Most asymmetry takes place on the first day after the shock. On the first day, for 637 out of 2,365 gasoline stations $(27 \%)$ the difference in the cumulative price change after a positive and negative shock is positive and significantly different from 0 . On day 2 the difference is positive and significant for 169 stations. After day 2, this number decreases further and becomes small.

\footnotetext{
${ }^{27}$ Although the intuitive interpretation of this percentage is straightforward, the exact interpretation is not obvious because it is not clear what this percentage would be if there were no asymmetric pricing. If I test once for each gasoline station the null hypothesis of symmetry at a 5\% significance level, then the test falsely rejects symmetry for $5 \%$ of the stations. As a consequence, I expect that if none of the gasoline stations adjust prices asymmetrically, the tests indicate that $5 \%$ of the stations do price asymmetrically. In my case this analysis is more complicated because I define a station as pricing asymmetrically if for at least 1 out of 25 days the difference is positive and different from 0 at the $5 \%$ significance level. I do not correct the reported percentages for this effect.
} 
Table 1 Percentage of stations that adjust prices asymmetrically and the total length of the asymmetric part of the transmission process

\begin{tabular}{l|c|c|c|c|}
\multirow{2}{*}{} & \multicolumn{2}{|c|}{ plus>minus } & \multicolumn{2}{c|}{ minus $>$ plus } \\
\cline { 2 - 5 } & number of stations & $\%$ of stations & number of stations & $\%$ of stations \\
\hline Total & 2,365 & & 2,365 & \\
0 days & 1,468 & $62 \%$ & 2,200 & $93 \%$ \\
1 day or more & 897 & $38 \%$ & 165 & $7 \%$ \\
\hline & & & & \\
1 day & 686 & $29 \%$ & 72 & $3 \%$ \\
2 days & 135 & $6 \%$ & 24 & $1 \%$ \\
3 days & 20 & $1 \%$ & 16 & $1 \%$ \\
4 days & 19 & $1 \%$ & 15 & $1 \%$ \\
5 days & 9 & $0 \%$ & 9 & $0 \%$ \\
6 days or more & 28 & $2 \%$ & 29 & $1 \%$
\end{tabular}

Third, I calculate the extent of the asymmetry. For each day I compute for the $38 \%$ of the gasoline stations that respond asymmetrically the average difference between the cumulative price change after the positive and negative 1 cent shock. Figure 4 shows the result. The asymmetry is on average 0.193 cent on the first day, but declines over time. One day after a 1 cent shock, the price of asymmetrically pricing stations increases on average by 0.346 cent after a positive shock and decreases on average by 0.153 cent after a negative shock. This means that a consumer pays at stations that adjust prices asymmetrically on average 0.193 cent more if it is a positive shock than what the consumer saves if it is a negative shock. On day 3 the difference is close to 0 . To place these numbers in perspective, Figure 4 also contains the average difference between the cumulative price change after a positive and negative shock for all 2,365 estimated gasoline stations (so including the stations that adjust prices asymmetrically). It shows the importance of measuring the extent of asymmetry at the firm level. The average extent of asymmetry in the first days differs substantially between all stations and the stations that adjust prices asymmetrically. On day 1 the mean of the difference over all stations is positive and equals 0.125 cent (this is close to the value from the pooled estimation). Thus, on day 1 the estimated extent of the asymmetry is on average 0.068 cent (54\%) larger when I only take into account stations that adjust prices asymmetrically. 
Figure 3 The days on which the transmission processes are asymmetric (the number of stations that respond asymmetrically per day)

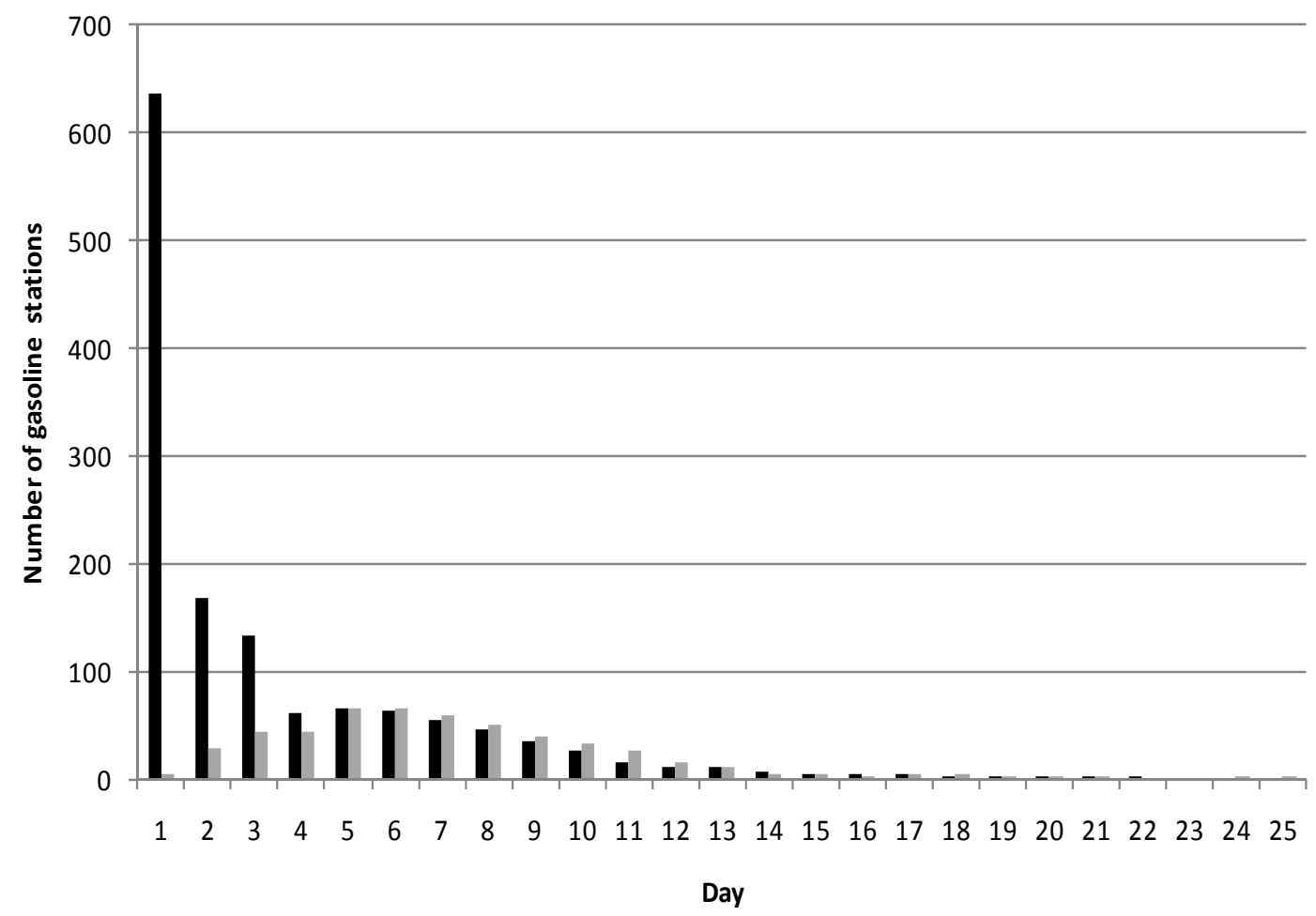

- plus $>$ minus stations minus $>$ plus stations

Figure 4 Average extent of asymmetry (difference between the cumulative adjustments)

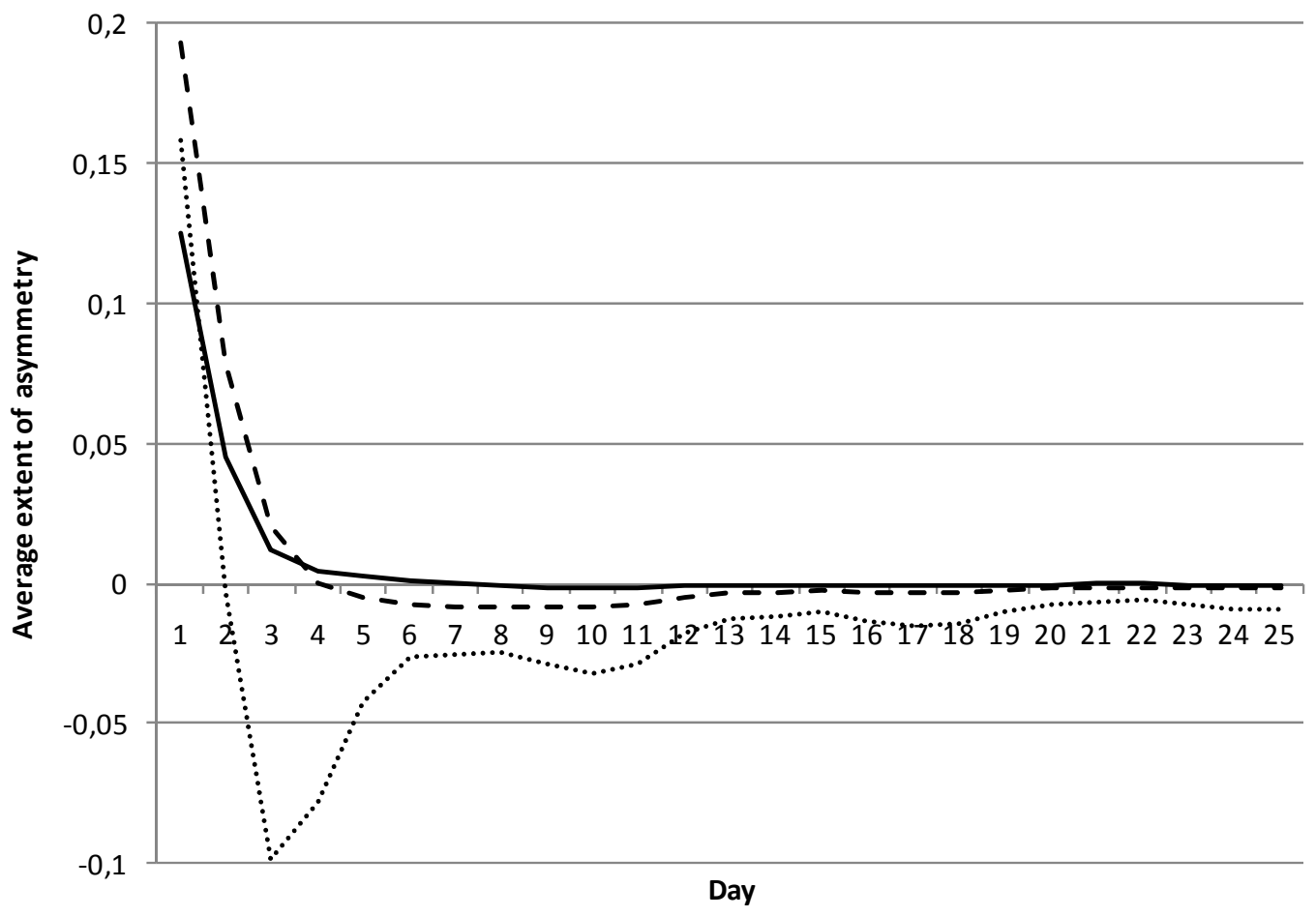


Fourth, to measure the length of the full transmission process, I calculate the number of days that it takes before the cumulative change in the retail price almost equals the long-run pass-through $\alpha_{i}^{*}$ (I calculate the number of days that the price is outside the interval $\left.\left\{0.975 \alpha_{i}^{*}, 1.025 \alpha_{i}^{*}\right\}\right)$. Figure 5a shows for all gasoline stations the length of the transmission process after a positive shock. For asymmetrically pricing stations it takes on average 9.8 days and for other stations 8.8 days. I also calculate the length of the transmission process after a negative shock. Figure $5 \mathrm{~b}$ depicts for each gasoline station the difference between the length of the transmission process after a positive and negative shock. For a majority of stations this difference is around zero (mean difference is 0.3 days). This indicates that the full pass-through of a positive and negative shock takes the same amount of time. However, for asymmetrically pricing stations the full transmission process is on average shorter after a negative shock than after a positive shock (1.1 days). This difference arises because asymmetrically pricing stations take more time in the case of a positive shock and a bit less time in the case of a negative shock compared to other stations. ${ }^{28}$

Up until now, I looked into the possibility that the pass-through of increases in the spot market price is faster than the pass-through of decreases. However, another possibility is that retail prices respond faster to decreases in the spot market price. The data show that gasoline stations do not often practice this type of pricing. I first calculate the percentage of gasoline stations that change their price faster after decreases than after increases. For each gasoline station, I compute the number of days on which the difference between the cumulative price change after a positive shock and after a negative shock is negative and significantly different from 0 at the $5 \%$ significance level. The fourth column of Table 1 shows that for $7 \%$ of the stations this occurs on at least one day. ${ }^{29}$ For most of these stations this effect takes just one day in total. Figure 3 shows for how many gasoline stations the difference is significantly negative on each day. This number is the highest on day 5 (67 stations) and declines afterward. Figure 4 shows the extent of the effect for the $7 \%$ of gasoline stations. The average

\footnotetext{
${ }^{28}$ The individual estimations show on average a shorter estimated length of the transmission process than the pooled estimation. This possibly indicates a summation bias. The maximum length of the transmission process after a positive shock and after a negative shock is according to the pooled estimation 15 days. According to the individual estimations, this number is on average 10.1 days.

${ }^{29}$ There are 104 stations for which the difference between the cumulative price change after a positive and a negative shock is both significantly positive and significantly negative at least once.
} 
difference is positive on day 1 , negative on day $2(0.079$ cent $)$ and subsequently moves in the direction of 0 .

As a robustness check, I also estimate Equation 3' with $\gamma_{i}^{+}=\gamma_{i}^{-}$and different maximum values for $v$, $w, x$, and $y$ (this enlarges the number of observations per station). Table 2 reports the results. The percentage of gasoline stations that adjust their prices asymmetrically is between $30 \%$ and $42 \%$, depending on the exact specification. The percentage of gasoline stations that respond faster to decreases than to increases in the spot market price varies between $1 \%$ and $8 \%$.

In Appendix A I study whether gasoline stations respond asymmetrically to the suggested price that is announced by their oil company. Again the results indicate that there exists heterogeneity of stations. I find that $22 \%$ of the gasoline stations adjust their retail prices asymmetrically to changes in the suggested price. The pass-through of shocks in the suggested price is faster than of shocks in the spot market price, although the extent of the asymmetry is similar. One day after a 1 cent increase in the suggested price, the price of stations that adjust prices asymmetrically rises on average by 0.903 cent. One day after a 1 cent decrease in the suggested price, the price at these stations declines on average by 0.698 cent. As a result, for stations that adjust prices asymmetrically there is an average asymmetry of 0.205 cent on day 1 . The difference with the estimated asymmetry at the market level is large, indicating the importance of the estimations per station. On day 1 the estimated asymmetry at the market level is only 0.043 cent. For asymmetrically pricing stations the transmission process after a positive shock takes on average 6.1 days. The asymmetric part of this transmission process for most stations is just one day and it takes place on the first days after the shock. 
Figure 5a Length of the transmission process after a positive shock

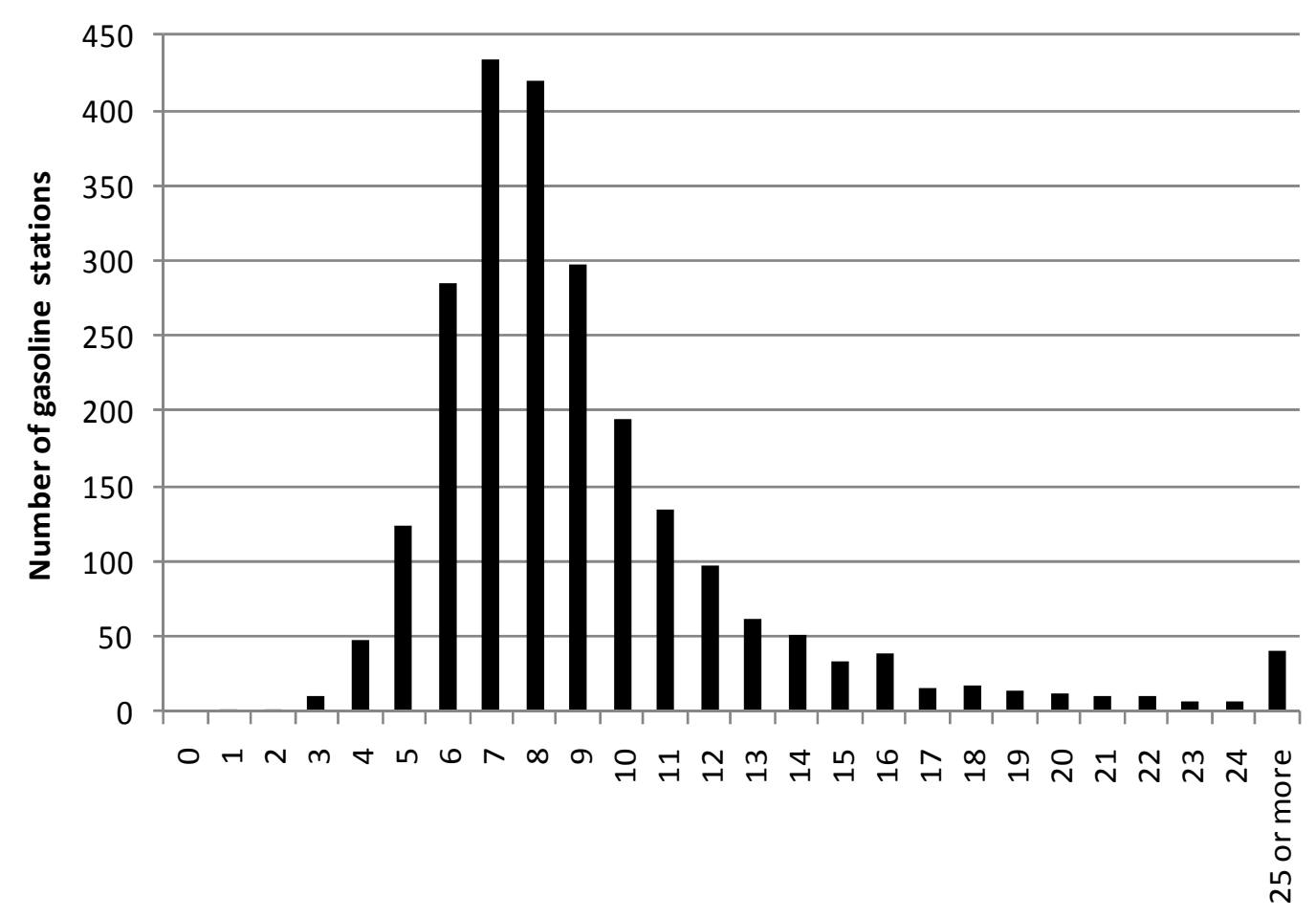

Number of days

Figure $5 \mathrm{~b}$ Difference in length of the transmission process after a positive and negative shock

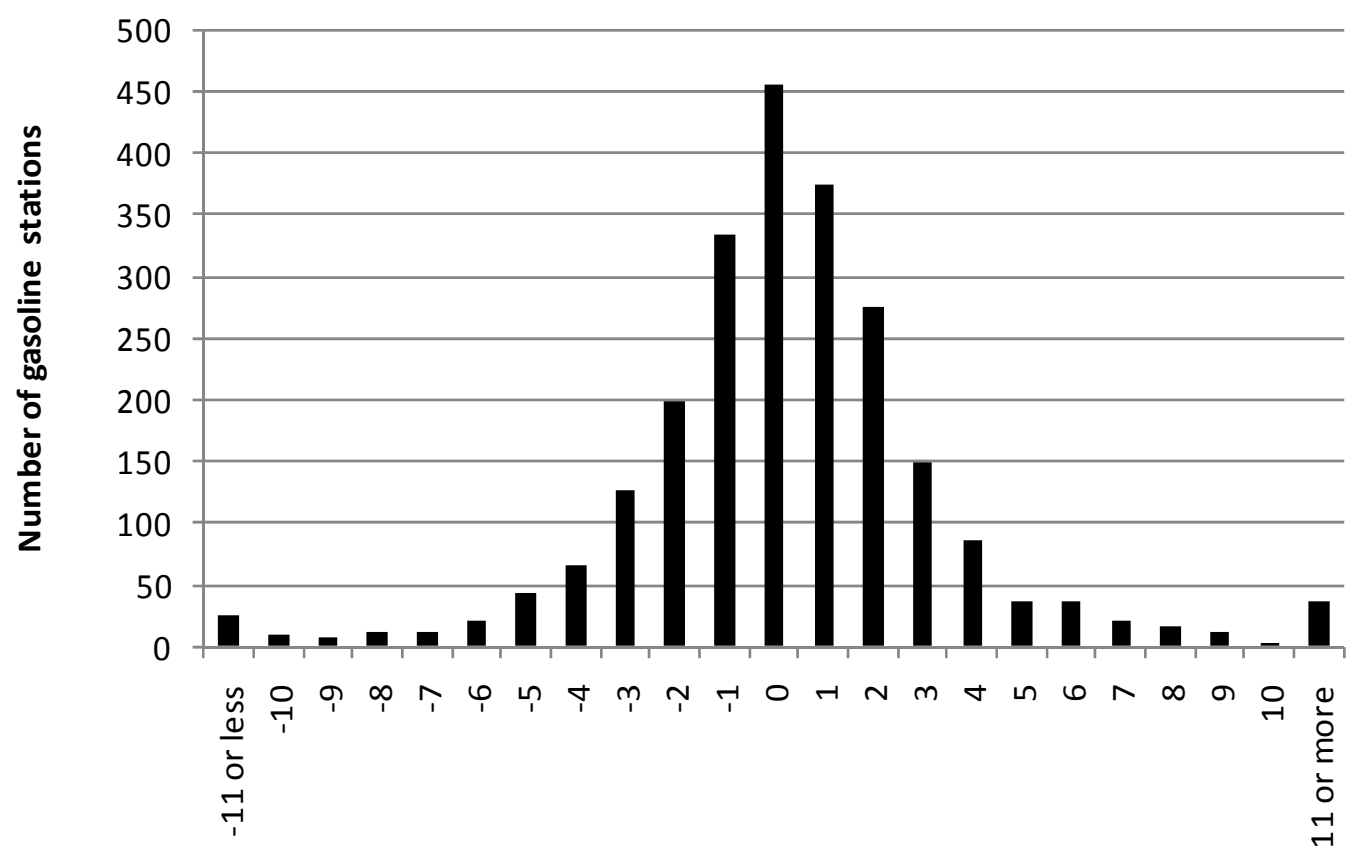

(Number of days after positive shock) - (Number of days after negative shock) 
Table 2 Alternative specifications for Equation 3'

\begin{tabular}{l|c|c|}
\multirow{2}{*}{} & \multicolumn{2}{|c|}{$\%$ of stations } \\
\cline { 2 - 3 } & plus>minus & minus>plus \\
\hline $\max v=w=x=y=3$ & $38 \%$ & $7 \%$ \\
$\max v=w=x=y=1$ & $38 \%$ & $7 \%$ \\
$\max v=w=x=y=0$ & $36 \%$ & $5 \%$ \\
$\max v=w=3, x=y=0$ & $42 \%$ & $8 \%$ \\
$\max v=w=3, x=y=0 ; \gamma_{i}^{+}=\gamma_{i}^{-}$ & $38 \%$ & $5 \%$ \\
$\max v=w=x=y=0 ; \gamma_{i}^{+}=\gamma_{i}^{-}$ & $30 \%$ & $1 \%$
\end{tabular}

Note: For all specifications I use the same 2,350 stations.

\section{What kind of gasoline stations respond asymmetrically?}

The previous section shows that there exists heterogeneity in the pricing behavior of gasoline stations: some stations adjust prices asymmetrically, while others do not. This shows that any explanation for price asymmetry has to be found at the firm level. Pure market level explanations of asymmetric price adjustments (for example, the nature of the production and distribution process or the volatility of the spot market price) would imply that all gasoline stations adjust prices asymmetrically.

This leads to the following questions: is there a systematic pattern in the type of stations that do price asymmetrically? Are there specific features that explain why stations price asymmetrically? Or is asymmetric pricing a more random phenomenon? Theoretical studies often explain asymmetric price adjustments by tacit collusion between retailers or a low search intensity of consumers. However, there exists no overarching theory that I can use to empirically test one theory against the other. For that reason, I do not try to answer why stations adjust prices asymmetrically, but I look at which stations adjust prices asymmetrically. I look for station-specific characteristics that are broad proxies for tacit collusion and/or a low search intensity. This "fishing expedition" may give input for further theoretical discussion on asymmetric pricing (Peltzman (2000) has a similar strategy). I find that characteristics of asymmetrically pricing stations and other stations do not differ much. Therefore, asymmetric pricing seems to be a random phenomenon in the population of gasoline stations. I first 
briefly discuss the two main theoretical explanations, then the methodology that I use, and finally I present the results.

$\underline{\text { Theory }}$

\section{Tacit collusion}

Tacit collusion can explain asymmetric pricing as follows (see also the interpretation of Verlinda (2008) of Rotemberg and Saloner (1986), Haltiwanger and Harington (1991), and Borenstein and Shepard (1996)). If wholesale costs rise, the difference between the monopoly price and wholesale costs declines. This makes short-term collusive profits lower, therefore collusion is less attractive and markups are lower. On the other hand, if wholesale costs go down, the difference between the monopoly price and wholesale costs goes up, short-term collusive profits are higher, collusion is more attractive and as a result markups are higher. So when wholesale costs go up, firms compete. When wholesale costs go down, firms tacitly collude and keep prices high. In practice, the change in wholesale costs is about the same for all gasoline stations. However, because the market characteristics that make tacit collusion easier to sustain may differ between stations and areas, it is possible that tacit collusion, and thereby asymmetric pricing, is only present in some areas. ${ }^{30}$

This form of tacit collusion is very subtle as a short-term strategy for gasoline retailing, since firms would switch frequently between collusion and competition because wholesale costs change on a daily basis. Balke, Brown, and Yücel (1998) offer an alternative explanation in which firms do not frequently switch between tacit collusion and competition. Suppose that stations are tacitly colluding and that stations are uncertain about the wholesale costs of other stations. Moreover, this tacit collusion is so profitable that stations do not want to risk that the cooperation comes to an end. If the wholesale costs for a station rise, the station immediately increases its price to signal that it still

\footnotetext{
${ }^{30}$ Borenstein, Cameron, and Gilbert (1997) have a different, but similar, explanation. Suppose stations are not colluding and ask the equilibrium price. If wholesale costs rise, the equilibrium price rises and stations increase their retail price as well. If wholesale costs decrease, all stations may earn higher profits if none of the stations immediately lower their price. In that case stations coordinate their prices with the previous retail price as focal point. Over time, prices return to the new lower equilibrium price because of random changes in demand and the risk that this occurs due to undercutting competitors.
} 
participates in the tacit agreement and that it does not try to cheat by lowering its margin. On the other hand, if the wholesale costs fall, the station is reluctant to lower its price because it might give the impression that the station is breaking the tacit agreement. As a result, stations respond asymmetrically to changes in the wholesale costs.

The following hypothesis tests if tacit collusion explains asymmetry. If a station can cooperate more easily with other stations and/or tacit collusion is more profitable, then there is a higher probability that it adjusts prices asymmetrically. For example, stations with the same brand can cooperate more easily and therefore I expect that an asymmetrically pricing station is more often surrounded by stations that have the same brand.

\section{Low search intensity}

A low search intensity can also cause asymmetric price adjustments (see Deltas (2008) and also Johnson (2002), Lewis (2005), Cabral and Fishman (2008), Yang and Ye (2008), and Tappata (2009)). Suppose consumers know the price for which they bought gasoline the previous time, but they do not know wholesale costs. If wholesale costs rise and a consumer comes to a gasoline station and sees a high retail price, the consumer does not know that the price has gone up because wholesale costs have gone up. So the consumer perceives this as a relatively high price and starts searching. As a result, there is strong competition and a low margin for the retailer. On the other hand, if wholesale costs decline, the consumer does not know this. A relatively high retail price still seems reasonable. The consumer does not search and this gives the retailer an opportunity to get a relatively high margin. In other words, the pass-through of wholesale cost changes is high when there is fierce competition because of high search intensity and low when there is less competition because of a low search intensity. Therefore asymmetry increases when search intensity decreases. ${ }^{31}$ The degree to which consumers search depends on the costs and benefits that are specific to areas, stations, and individuals. For that reason it is possible that asymmetry is only present in some regions or at some stations.

\footnotetext{
${ }^{31}$ Janssen, Pichler, and Weidenholzer (2009) consider a sequential search model with incompletely informed consumers and study a specific gasoline retail market. Among other things, they find that prior beliefs of consumers about costs are important for explaining price distributions.
} 
The following hypothesis tests if a low search intensity explains asymmetric pricing. If a station is subject to a low profitability of search (high search costs or low search revenues) and/or is located in a region with a low number of searchers, then there is a higher probability that it adjusts prices asymmetrically. For example, income per capita is a proxy for the opportunity costs of searching, therefore I expect that asymmetrically pricing stations are more often located in areas with a high income per capita.

\section{$\underline{\text { Method }}$}

It is difficult to empirically test the two aforementioned hypothesis against each other. Often it is possible to link an empirical observation to asymmetric pricing via both theoretical explanations. For example, Verlinda (2008) links market power to asymmetric pricing via tacit collusion and Deltas (2008) via a low search intensity. Another example is the number of competitors nearby a station. On the one hand, fewer competitors make it easier to tacitly collude and increases the probability that a station prices asymmetrically. On the other hand, fewer competitors increase consumers' search costs, so a low search intensity can also be the cause of the higher probability. Therefore, I link characteristics of stations to asymmetric pricing, but I do not try to provide a comprehensive answer on the process that leads to the empirical relation.

I divide all tested gasoline stations into two groups: one group with stations that adjust prices asymmetrically and one group with all other stations. I study whether stations in these two groups have similar characteristics. For both groups I calculate for each characteristic the average value of this characteristic over all stations in the group or the share of stations in the group with this characteristic. Afterward, I test for equality of the averages or shares via a t-test.

For each gasoline station I use 35 (sometimes overlapping) characteristics. Besides characteristics of individual stations, I also look at characteristics of the area in which a station is located. I take the 3 digit zip code area in which a station is located as a proxy for its direct market and the 2 digit zip code area as a proxy for its broader market. The Netherlands consists of 90 areas at the 2 digit zip code level 
(average size $375 \mathrm{~km}^{2}$, average number of stations 44 ) and 829 areas at the 3 digit zip code level (average size $41 \mathrm{~km}^{2}$, average number of stations 5). ${ }^{32}$ Smaller areas do not provide more information.

Roughly, I include 5 kinds of station-specific characteristics: brand indicators (e.g., the specific brand and the ownership structure), location indicators (e.g., location along the highway, location near the border, and population size of the 3 digit zip code area in which the station is located), competitor indicators (e.g., the number of stations in the area in which a station is located), price indicators (e.g., the margin of the station), and search intensity indicators (e.g., the percentage of people aged 60 or older in the 3 digit zip code area where the station is located). The characteristics are broad proxies (or conditions) for the existence of tacit collusion and/or a low search intensity. Often the characteristics have a relation with both hypotheses.

\section{$\underline{\text { Results }}$}

Table 3 shows the results of the calculations. The interpretation of the first line of the table is as follows: the first and second column show that $53 \%$ of all stations that adjust prices asymmetrically are company-owned while, of all other stations, 55\% are company-owned. The third column shows the p-value of the t-statistic (null hypothesis of the t-test: the two percentages are equal). There is no significant difference between the two groups at all usual significance levels, so company ownership does not have a higher incidence in one of the two groups.

None of the characteristics show a substantial difference between the group of asymmetrically pricing stations and the group of all other stations. Of the 35 characteristics in the table, only 4 are significantly different at the $1 \%$ significance level. However, the economic impact of these 4 differences is small. I will first discuss the statistically significant results and then a few others.

\footnotetext{
${ }^{32}$ Some 3 digit zip code areas do not contain many stations. However, for all non-reported 2 digit zip code characteristics, the 3 digit equivalents provide similar results.
} 
Table 3 Characteristics of the group with asymmetrically pricing stations and the group with all other stations

\begin{tabular}{|c|c|c|c|}
\hline & $\begin{array}{l}\text { Asymmetrically } \\
\text { pricing group }\end{array}$ & $\begin{array}{c}\text { All other } \\
\text { stations group }\end{array}$ & $\begin{array}{l}\text { Equality: } \\
\text { p-value }\end{array}$ \\
\hline Number of stations in group & 897 & 1,468 & \\
\hline \multicolumn{4}{|l|}{ Brand indicators } \\
\hline Share of comp-owned stats & $53 \%$ & $55 \%$ & 0.18 \\
\hline Av $\%$ of comp-owned stats in 3 dig zip & $45 \%$ & $47 \%$ & 0.14 \\
\hline Share of Brand A stats & $11 \%$ & $15 \%$ & $0.02 *$ \\
\hline Share of Brand B stats & $14 \%$ & $10 \%$ & $0.00 * *$ \\
\hline Share of Brand C stats & $27 \%$ & $23 \%$ & $0.04 *$ \\
\hline Share of Brand D stats & $10 \%$ & $13 \%$ & 0.13 \\
\hline Share of Brand E stats & $10 \%$ & $12 \%$ & $0.03 *$ \\
\hline Share of branded stats & $73 \%$ & $74 \%$ & 0.81 \\
\hline Av concentration ratio 5 largest brands in 3 dig zip & 0.62 & 0.62 & 0.79 \\
\hline Av $\%$ of stats with own brand in 3 dig zip & $31 \%$ & $30 \%$ & 0.52 \\
\hline Av $\%$ of stats with largest brand in 3 dig zip & $33 \%$ & $33 \%$ & 0.63 \\
\hline \multicolumn{4}{|l|}{ Location indicators } \\
\hline Share of highway stats & $14 \%$ & $11 \%$ & 0.05 \\
\hline Av $\%$ of highway stats in 3 dig zip & $10 \%$ & $8 \%$ & $0.00 * *$ \\
\hline Av size of population in 3 dig zip & 34,358 & 34,492 & 0.89 \\
\hline Av car/population ratio in 3 dig zip & $61 \%$ & $61 \%$ & 0.65 \\
\hline Share of stats in 2 dig zip next to German border & $18 \%$ & $16 \%$ & 0.28 \\
\hline Share of stats in 2 dig zip next to Belgian border & $13 \%$ & $13 \%$ & 0.76 \\
\hline \multicolumn{4}{|l|}{ Competitor indicators } \\
\hline Av $\%$ of other asym pricing stats in 2 dig zip & $39 \%$ & $37 \%$ & $0.01 *$ \\
\hline Av \% of other asym pricing stats in 3 dig zip & $40 \%$ & $37 \%$ & $0.00 * *$ \\
\hline Av nr of stats in 2 dig zip & 51 & 50 & $0.05^{*}$ \\
\hline Av nr of stats in 3 dig zip & 8 & 8 & 0.93 \\
\hline Av nr of stats per 1,000 inhab in 2 dig zip & 0.26 & 0.25 & 0.32 \\
\hline Av nr of stats per 1,000 inhab in 3 dig zip & 0.29 & 0.30 & 0.86 \\
\hline \multicolumn{4}{|l|}{ Price indicators } \\
\hline Av (retail price - spot price) for stat & $€ 0.116$ & $€ 0.114$ & 0.23 \\
\hline Av (retail price - spot price) of other stats in 2 dig zip & $€ 0.112$ & $€ 0.113$ & 0.06 \\
\hline Av (retail price - spot price) of other stats in 3 dig zip & $€ 0.112$ & $€ 0.112$ & 0.64 \\
\hline Av \% of days with price change & $36 \%$ & $36 \%$ & 0.12 \\
\hline
\end{tabular}

Table 3 continues on next page 
Table 3 (continued)

\begin{tabular}{l|c|c|c|} 
& $\begin{array}{c}\text { Asymmetrically } \\
\text { pricing group }\end{array}$ & $\begin{array}{c}\text { All other } \\
\text { stations group }\end{array}$ & $\begin{array}{c}\text { Equality: } \\
\text { p-value }\end{array}$ \\
\hline Search intensity indicators & & & 0.051 \\
Av rank reversal of a stat's area in 2 dig zip & 0.055 & 0.056 & 0.47 \\
Av rank reversal of a stat's area in 3 dig zip & $€ 0.028$ & $€ 0.028$ & 0.88 \\
Av spread of prices other stats in 2 dig zip & $€ 0.026$ & $€ 0.026$ & 0.92 \\
Av spread of prices other stats in 3 dig zip & $21 \%$ & $21 \%$ & 0.52 \\
Av \% aged 60 or older in 3 dig zip & $3 \%$ & $3 \%$ & 0.90 \\
Av \% unemployed in municipality & $17 \%$ & $17 \%$ & 0.22 \\
Av \% immigrants in 3 dig zip & $€ 2,029$ & $€ 2,033$ & 0.70 \\
Av income per capita in 3 dig zip & & & \\
& & & \\
Number of company-owned stations in group & 472 & $€ 0.112$ & $0.00 * *$
\end{tabular}

Notes: * and ** indicate significance at the 5 percent and 1 percent levels, respectively. "Share of $x$ stats" means share of stations in the group with characteristic $x$. "Av $x$ " means average of characteristic $x$ over all stations in the group.

First, I discuss whether asymmetrically pricing stations are closely located to each other. I look at three levels of geographic concentration: the 3 digit zip code level, the 2 digit zip code level, and the national level. I calculate the percentage of other stations that price asymmetrically in the zip code area of a station. Table 3 shows that this percentage is on average significantly higher for stations that adjust prices asymmetrically themselves. So there is a geographic concentration of stations that price asymmetrically at both the 2 and 3 digit zip code level. Although statistically significant, this effect is very small. To illustrate, stations that do not set prices asymmetrically are located in 3 digit zip code areas where on average $37 \%$ of the other stations set prices asymmetrically, while stations that do set prices asymmetrically are located in areas where on average $40 \%$ of the other stations price asymmetrically. To study clustering at the national level, Figure 6 shows the percentage of stations that adjust prices asymmetrically in each 2 digit zip code area. Zip codes with numbers that are close to each other are roughly in the same part of the country. The figure shows that a substantial part of the stations adjust prices asymmetrically in all zip code areas and that areas with a high percentage are not close to each other. So asymmetrically pricing stations are present all over the country. 
Figure 6 Percentage of asymmetrically pricing stations per 2 digit zip code area

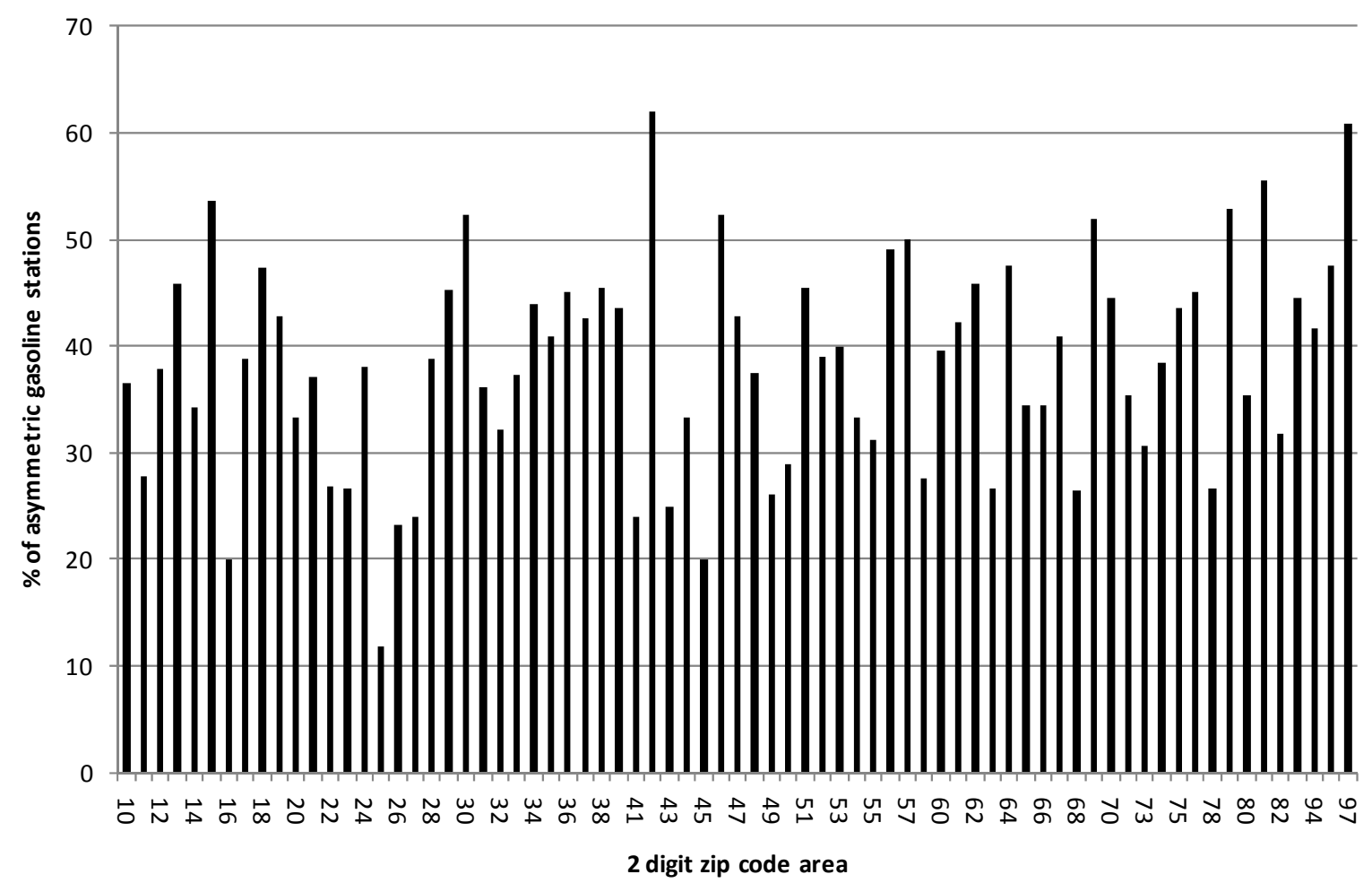

Note: The figure depicts only areas with 15 or more stations.

A second characteristic that is statistically different is the percentage of highway stations in the 3 digit zip code area of a station. For asymmetrically pricing stations the average percentage of highway stations in the 3 digit zip code area is significantly higher than for all other stations. The size of the effect is moderate $(10 \%$ vs. $8 \%)$. Third, stations that adjust prices asymmetrically are significantly more likely to be of certain brands, although the differences are not substantial.

The final significant result is the difference in markup for company-owned stations. I look at markups as a proxy for market power. Verlinda (2008) notes that stations with higher retail prices do not necessarily have higher markups and more local market power, because it is possible that oil companies do not charge the same wholesale price to all dealer-owned stations. However, for company-owned stations the difference between the retail price and spot market price is the true markup. The lowest line of Table 3 depicts the average difference between the retail price and spot market price for the groups of company-owned stations that do and do not set prices asymmetrically. It 
shows that company-owned stations that price asymmetrically have on average a statistically significant higher markup of 0.5 cent (the difference between the highest and lowest markup of the tested company-owned stations is 12.5 cents). If I consider all stations (company- and dealer-owned), then stations that adjust prices asymmetrically do not have a higher price on average.

All other characteristics in the table do not statistically differ between asymmetrically pricing stations and all other stations. All these characteristics and their intuition are relatively straightforward, with a few exceptions that I now discuss. First, I look at the rank reversal of a station's area. Retailers can increase search costs via their pricing behavior. If there is not a consistent price ranking of stations (i.e., stations often become cheaper or more expensive compared to each other), then there is a higher degree of imperfect information among consumers (higher search costs). ${ }^{33}$ To measure this temporal price dispersion across stations (or say: the degree to which consumers are uncertain about which firms are cheap) I calculate the rank reversals (Chandra and Tappata (2008)). ${ }^{34}$ More specifically, I calculate for each gasoline station the average of the rank reversals between all its competitors in the 2 and 3 digit zip code area where the station is located. This average rank reversal (say: the rank reversal of a station's area) is a proxy for the degree of uncertainty about prices in the market of this station (I exclude the station itself because if it adjusts prices asymmetrically, this might lead to a higher rank reversal). Table 3 presents the average rank reversal of a station's area for both groups of stations. There is no difference between the groups.

A second characteristic that is not straightforward is the average spread of prices of other stations in an area. I proxy station-specific search costs for a consumer by the price spread between stations. If there are still high potential gains of search in the area around a station, search costs in the market of

\footnotetext{
${ }^{33}$ According to standard search models (Varian (1980)), under imperfect information the ranking of retail prices differs over time. Retailers differentiate between consumers that are fully informed and ones that have to search for price quotations.

${ }^{34}$ Chandra and Tappata (2008) define the rank reversal as follows. The vector $s_{i, j}$ contains the price spread between two stations $(i, j)$ over $T_{i, j}$ days such that station $i$ has most often the highest price. The rank reversal between station $i$ and $j$ is the proportion of observations where $P_{j, t}>P_{i, t}$ :$$
r_{i, j}=\frac{1}{T_{i, j}} \sum_{t=1}^{T_{i, j}} I_{\left\{P_{j, t}>P_{i, t}\right\}}
$$

A rank reversal of 0.05 means that the station which has most often the lowest price, has at $5 \%$ of the observations the highest price.
} 
that station must be high. ${ }^{35}$ For each station I take the mean of the average price spread between all possible pairs of competitors in the zip code area. The table shows that there is no difference between the two groups.

The final characteristics that are not straightforward are the characteristics of consumers in the area around a gasoline station. The share of people in an area that are 60 years or older, unemployed, or immigrant is a proxy for the number of searchers (Lach (2007) argues that immigrants can have different search costs). The results are similar for stations in both groups. Income is a measure of a consumer's opportunity cost of search. The table shows that income per capita is not higher around stations that adjust prices asymmetrically.

To summarize this section, I find that none of the characteristics in my data set differ substantially between stations that do and do not adjust prices asymmetrically. Although asymmetrically pricing stations differ in some aspects, the economic significance of these differences is small. None of the proxies provide strong encouragement for either the tacit collusion or the low search intensity hypothesis. Asymmetric pricing seems to be a phenomenon that occurs randomly in the population of gasoline stations. ${ }^{36}$

\section{Conclusion}

This paper examines whether oil companies and gasoline stations adjust prices asymmetrically. It also studies differences in characteristics of stations that do and do not adjust prices asymmetrically.

None of the oil companies adjust suggested prices asymmetrically to changes in the spot market price. I do find heterogeneity in the way individual gasoline stations set prices. The majority of stations do

\footnotetext{
${ }^{35}$ Chandra and Tappata (2008) show that in general the relation between search intensity and price dispersion is non-monotonic.

${ }^{36}$ I also perform the same analysis as in this section on stations that respond asymmetrically to the suggested price (see Appendix A). I find that a substantial part of the stations that adjust their retail price asymmetrically to changes in the suggested price have the same brand. Of the stations that adjust prices asymmetrically, $39 \%$ have Brand A vs. $13 \%$ of all the other stations (p-value of the t-test for equality is 0.00 ). I cannot explain this result (remember from Figure 1 that the suggested price of Brand A responds symmetrically to the spot market price). Possibly, institutional factors like contracts between the oil company and gasoline stations play a role. Except the specific brand characteristics, none of the characteristics statistically differ between the two groups.
} 
not adjust prices asymmetrically, but $38 \%$ of the stations do. One day after a change in the spot market price, the asymmetry is substantial for these stations (on average 0.193 cent after a 1 cent shock), but this asymmetry disappears for most stations after one or two days. I do not find a clear pattern in the characteristics of asymmetrically pricing stations. Asymmetric pricing seems to be a phenomenon that occurs randomly across individual gasoline stations. The analysis does not provide indications that strongly suggest that tacit collusion or a low search intensity is an important explanation for asymmetry.

In this study I use data on decisions of almost all individual decision makers in the Netherlands. These data have a similar frequency as pricing decisions and cost changes. This data set gives the possibility to study the asymmetric pricing behavior of individual firms and to measure the degree of heterogeneity. Previous research mainly focuses on asymmetry at the market level. I also minimize a possible bias caused by aggregation over time and rule out a possible bias caused by aggregation over individuals. This microdata study shows that differences between individual firms are important for a proper understanding of asymmetric pricing. 


\section{References}

Bachmeier, Lance J. and James M. Griffin. (2003) "New Evidence on Asymmetric Gasoline Price Responses." Review of Economics and Statistics, 85(3), pp. 772-776.

Balke, Nathan S., Stephen P. A. Brown, and Mine K. Yücel. (1998) "Crude Oil and Gasoline Prices: An Asymmetric Relationship?" Federal Reserve Bank of Dallas Economic Review, First Quarter, pp. 2-11.

Balmaceda, Felipe and Paula Soruco. (2008) "Asymmetric Dynamic Pricing in a Local Gasoline Retail Market.” Journal of Industrial Economics, 56(3), pp. 629-653.

Bettendorf, Leon, Stéphanie A. van der Geest, and Gerard H. Kuper. (2009) "Do Daily Retail Gasoline Prices Adjust Asymmetrically?” Journal of Applied Statistics, 36(4), pp. 385-397.

Bettendorf, Leon, Stéphanie A. van der Geest, and Marco Varkevisser. (2003) "Price Asymmetry in the Dutch Retail Gasoline Market.” Energy Economics, 25(6), pp. 669-689.

Borenstein, Severin, A. Colin Cameron, and Richard Gilbert. (1997) "Do Gasoline Prices Respond Asymmetrically to Crude Oil Price Changes?" Quarterly Journal of Economics, 112(1), pp. 305-339.

Borenstein, Severin and Andrea Shepard. (1996) "Dynamic Pricing in Retail Gasoline Markets." RAND Journal of Economics, 27(3), pp. 429-451.

BOVAG. (2006) Tankstations in cijfers 2006-2007. Bunnik.

Cabral, Luís and Arthur Fishman. (2008) "Business as Usual: A Consumer Search Theory of Sticky Prices and Asymmetric Price Adjustment.” Working Paper.

Chandra, Ambarish and Mariano Tappata. (2008) "Consumer Search and Dynamic Price Dispersion. An Application to Gasoline Markets." Working Paper.

Choi, In. (2001) "Unit Root Tests for Panel Data." Journal of International Money and Finance, 20(2), pp. 249-272.

Deltas, George. (2008) "Retail Gasoline Price Dynamics and Local Market Power." Journal of Industrial Economics, 56(3), pp. 613-628.

Driscoll, John C. and Aart C. Kraay. (1998) "Consistent Covariance Matrix Estimation with Spatially Dependent Panel Data." Review of Economics and Statistics, 80(4), pp. 549-560.

Eckert, Andrew and Douglas S. West. (2004) "Retail Gasoline Price Cycles across Spatially Dispersed Gasoline Stations.” Journal of Law and Economics, 47(1), pp. 245-273.

Faber, Riemer P. and Maarten C. W. Janssen. (2008) "On the Effects of Suggested Prices in Gasoline Markets.” Tinbergen Institute Discussion Paper 08-116/1.

Frey, Giliola and Matteo Manera. (2007) "Econometric Models of Asymmetric Price Transmission." Journal of Economic Surveys, 21(2), pp. 349-415.

Geweke, John. (2004) "Issues in the Rockets and Feathers Gasoline Price Literature." Report to Federal Trade Commission.

Haltiwanger, John and Joseph E. Harrington, Jr. (1991) "The Impact of Cyclical Demand Movements on Collusive Behavior." RAND Journal of Economics, 22(1), pp. 89-106.

Hoechle, Daniel. (2007) "Robust Standard Errors for Panel Regressions with Cross-Sectional Dependence." Stata Journal, 7(3), pp. 281-312. 
Hosken, Daniel S., Robert S. McMillan, and Christopher T. Taylor. (2008) "Retail Gasoline Pricing: What Do We Know?” International Journal of Industrial Organization, 26(6), pp. 1425-1436.

Janssen, Maarten C. W., Paul Pichler, and Simon Weidenholzer. (2009) "Sequential Search with Incompletely Informed Consumers: Theory and Evidence from Retail Gasoline Markets." Working Paper.

Johnson, Ronald N. (2002) "Search Costs, Lags, and Prices at the Pump." Review of Industrial Organization, 20(1), pp. 33-50.

Kao, Chihwa. (1999) "Spurious Regression and Residual-Based Tests for Cointegration in Panel Data." Journal of Econometrics, 90(1), pp. 1-44.

Lach, Saul. (2007) “Immigration and Prices.” Journal of Political Economy, 115(4), pp. 548-587.

Lewis, Matthew. (2005) “Asymmetric Price Adjustment and Consumer Search: An Examination of the Retail Gasoline Market.” Working Paper.

Lewis, Matthew and Michael Noel. (2009) "The Speed of Gasoline Price Response in Markets with and without Edgeworth Cycles." Working Paper.

Maddala, G. S. and Shaowen Wu. (1999) "A Comparative Study of Unit Root Tests with Panel Data and a New Simple Test." Oxford Bulletin of Economics and Statistics, 61(S1), pp. 631-652.

Noel, Michael. (2009) "Do Retail Gasoline Prices Respond Asymmetrically to Cost Shocks? The Influence of Edgeworth Cycles." RAND Journal of Economics, 40(3), pp. 582-595.

Peltzman, Sam. (2000) “Prices Rise Faster than They Fall.” Journal of Political Economy, 108(3), pp. 466-502.

Radchenko, Stanislav. (2005) "Oil Price Volatility and the Asymmetric Response of Gasoline Prices to Oil Price Increases and Decreases." Energy Economics, 27(5), pp. 708-730.

Rotemberg, Julio J. and Garth Saloner. (1986) "A Supergame-Theoretic Model of Price Wars during Booms.” American Economic Review, 76(3), pp. 390-407.

Shell. (2001) "Het is echt heel transparant. Hoe ontstaan de adviesprijzen voor benzine?" Shell Venster, July/August, pp. 16-18.

Tappata, Mariano. (2009) "Rockets and Feathers: Understanding Asymmetric Pricing." RAND Journal of Economics, 40(4), pp. 673-687.

Varian, Hal R. (1980) “A Model of Sales.” American Economic Review, 70(4), pp. 651-659.

Verlinda, Jeremy A. (2008) "Do Rockets Rise Faster and Feathers Fall Slower in an Atmosphere of Local Market Power? Evidence from the Retail Gasoline Market." Journal of Industrial Economics, 56(3), pp. 581-612.

Yang, Huanxing and Lixin Ye. (2008) "Search with Learning: Understanding Asymmetric Price Adjustments." RAND Journal of Economics, 39(2), pp. 547-564. 


\section{Appendix A}

\section{Do gasoline stations respond asymmetrically to changes in the suggested price?}

In Section 4 I study whether gasoline stations respond asymmetrically to changes in the spot market price. In this appendix I study whether stations respond asymmetrically to changes in the suggested price of their oil company. Since suggested prices are only available for the five largest oil companies, I only use stations that operate under the brand of one of the five largest oil companies $(2,318$ of the 4,004 stations in the sample). Like in Section 4, I estimate an asymmetric error correction model. The long-run relation between the suggested price and retail price is:

$$
P_{i, t}=\alpha_{i}^{*} \operatorname{Sug}_{i, t}+c_{i}^{*}+\varepsilon_{i, t}^{*}
$$

where $\operatorname{Sug}_{i, t}$ now refers to the suggested price of the oil company of the brand of station $i$ at day $t$. Moreover, $c_{i}^{*}$ now reflects the average difference between the retail price and the suggested price.

First, I specify a symmetric relation between the retail price and suggested price: ${ }^{37}$

$$
\Delta P_{i, t}=\sum_{j=0}^{k} \alpha_{i, j} \Delta \operatorname{Sug} g_{i, t-j}+\sum_{j=1}^{l} \beta_{i, j} \Delta P_{i, t-j}+\gamma_{i} \varepsilon_{i, t-1}^{*}+\mu_{i, t}
$$

I also specify an asymmetric relation:

$$
\begin{aligned}
\Delta P_{i, t}= & \sum_{j=0}^{v} \alpha_{i, j}^{+} \Delta \operatorname{Sug}_{i, t-j}^{+}+\sum_{j=0}^{w} \alpha_{i, j}^{-} \Delta \operatorname{Sug}_{i, t-j}^{-} \\
& +\sum_{j=1}^{x} \beta_{i, j}^{+} \Delta P_{i, t-j}^{+}+\sum_{j=1}^{y} \beta_{i, j}^{-} \Delta P_{i, t-j}^{-}+\gamma_{i}^{+} \varepsilon_{i, t-1}^{*+}+\gamma_{i}^{-} \varepsilon_{i, t-1}^{*_{-}}+\mu_{i, t}
\end{aligned}
$$

As in Section 4, I estimate the equations when all gasoline stations are pooled and for each individual gasoline station. I use the same estimation methods as in Section 4.

\footnotetext{
${ }^{37}$ Gasoline stations could use more recent information on the spot market price than is available in the suggested price. On the day that oil companies decide on the suggested price ( $t-1)$, they only have limited knowledge on the spot market price of that day (see Section 2 and Footnote 22). However, at the moment that gasoline stations decide on their retail price (the morning of $t$ ), they could know the spot market price of day $t-1$. The data do not suggest that retailers widely use this information in practice.
} 


\section{All stations pooled}

I first estimate the pooled equation. The panel cointegration test of Kao (1999) reveals homogeneous cointegration between retail prices and suggested prices. The estimated coefficient for the long-run impact of the suggested price is 0.991 (standard error equals 0.001 ).

Figure A1 shows the cumulative adjustment function for the specification with $v=w=x=y=1$ (the cumulative adjustment functions for other specifications are similar). ${ }^{38}$ It shows that there is significant asymmetry. The difference between the cumulative changes in the retail prices is positive and significant on the first day after the shock. On day 1, the pass-through of a 1 cent change in the suggested price is 0.860 cent after an increase and only 0.816 cent after a decrease. After day 1 this difference declines slowly over time. ${ }^{39}$ After 16 days, retail prices have adsorbed more than $97.5 \%$ of both the positive and negative shock. ${ }^{40}$ I take a look at the disaggregated level in the next paragraphs.

\section{$\underline{\text { Individual stations }}$}

I first estimate Equation A1 and afterward Equation A3 for 1,616 individual gasoline stations. ${ }^{41}$ The average estimated long-run impact of the suggested price on the retail price is 0.992 (standard deviation is 0.036 ). I calculate a cumulative adjustment function for every gasoline station.

\footnotetext{
${ }^{38}$ The specification that I present uses in total 2,193 stations and 828,718 observations.

${ }^{39}$ The difference between the positive and negative shock is also statistically different from 0 on days 14 up to 19.

${ }^{40}$ After 25 days, the sum of the differences between the positive and negative cumulative adjustment equals 0.215 cent. Analogous to Footnote 24, all consumers together pay 30,716 euros more after a 1 cent increase in the suggested price than they save after an equal decrease.

${ }^{41}$ The sample contains 2,318 stations with the brand of one of the five largest oil companies. For 1,800 stations there is enough data to estimate both Equation A1 and A3. I exclude 42 stations because the residual-based test for cointegration could not reject the null of no cointegration in Equation A1 (all price series of the estimated stations are integrated of order 1). Furthermore, I exclude 45 stations because the estimated $\gamma_{i}^{+}$or $\gamma_{i}^{-}$in Equation A3 is larger than 0 or smaller than -2 and 97 stations for which 20 or fewer observations that differ from 0 are available for estimating one of the parameters in Equation A3 (more restrictive conditions do not change results much). There are 1,616 stations left. I correct for 651 of these 1,616 stations the standard errors for heteroskedasticity and for 857 stations for heteroskedasticity and serial correlation.
} 
Figure A1 Cumulative adjustment of retail prices (after suggested price change, pooled estimation)

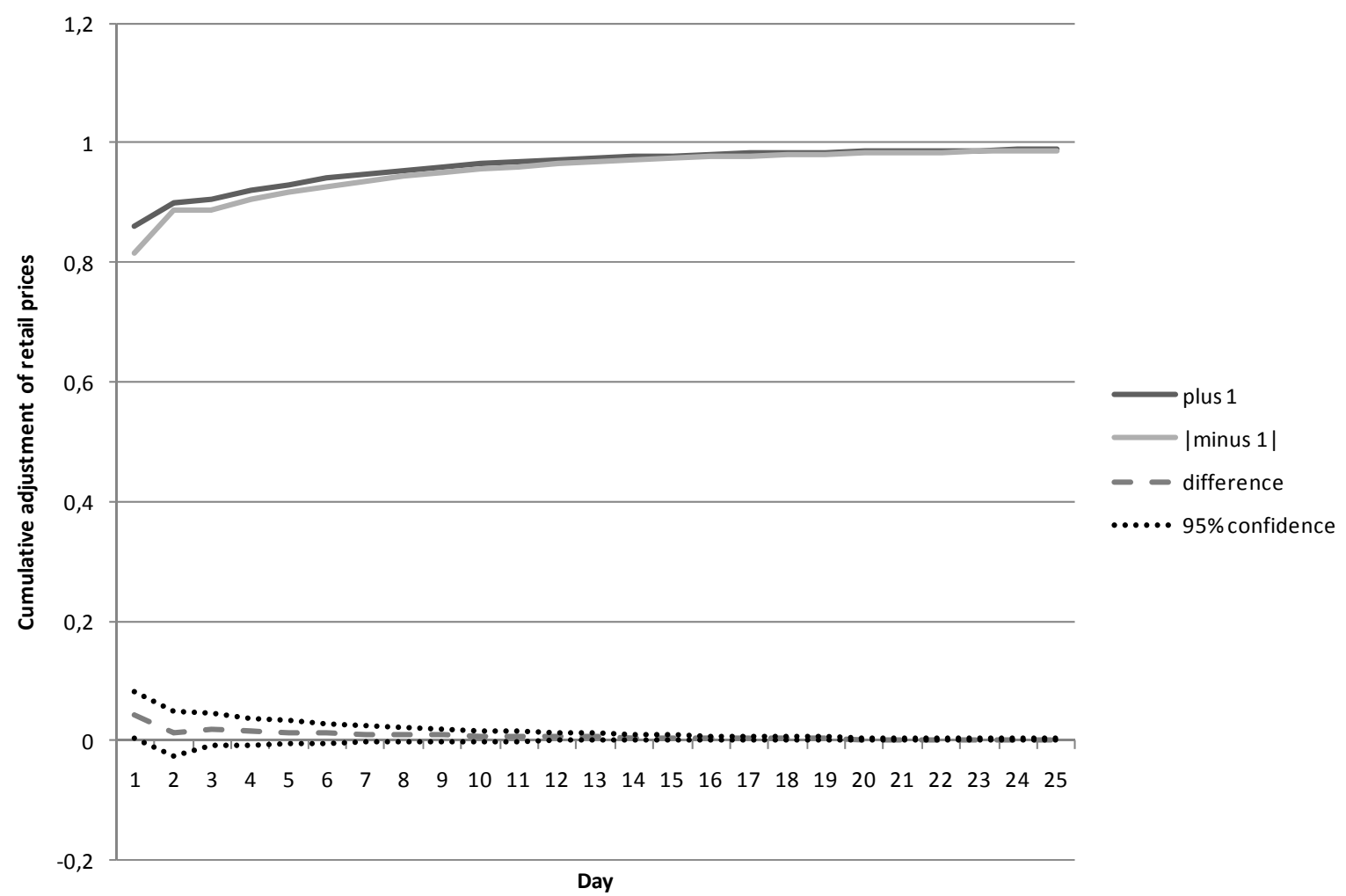

First, I calculate the percentage of gasoline stations that respond asymmetrically to changes in the suggested price. I count for each station the number of days on which the cumulative change in the retail price after the positive shock is significantly larger than the cumulative change in the retail price after the negative shock. Table A1 reports the results. Many gasoline stations do not adjust prices asymmetrically, but a substantial part of the gasoline stations do. The table shows that for $22 \%$ of the gasoline stations the transmission process is asymmetric on at least one day. However, only a small part of the transmission process of these stations is asymmetric. For the majority of the stations that adjust their prices asymmetrically, the asymmetry exists for only 1 day in total. 
Table A1 Percentage of stations that adjust prices asymmetrically (after a change in the suggested price) and the total length of the asymmetric part of the transmission process

\begin{tabular}{l|c|c|c|c|}
\multirow{2}{*}{} & \multicolumn{2}{|c|}{ plus>minus } & \multicolumn{2}{c|}{ minus >plus } \\
\cline { 2 - 5 } & number of stations & $\%$ of stations & number of stations & $\%$ of stations \\
\hline Total & 1,616 & & 1,616 & \\
0 days & 1,254 & $78 \%$ & 1,441 & $89 \%$ \\
1 day or more & 362 & $22 \%$ & 175 & $11 \%$ \\
\hline & & & & \\
1 day & 147 & $9 \%$ & 80 & $5 \%$ \\
2 days & 62 & $4 \%$ & 25 & $2 \%$ \\
3 days & 47 & $3 \%$ & 14 & $1 \%$ \\
4 days & 21 & $1 \%$ & 8 & $0 \%$ \\
5 days & 11 & $1 \%$ & 4 & $0 \%$ \\
6 days or more & 74 & $5 \%$ & 44 & $3 \%$
\end{tabular}

Figure A2 shows on which days the transmission processes of the gasoline stations are asymmetric. For each day the figure shows the number of stations for which the difference between the cumulative price change after the positive and negative shock is positive and significantly different from 0 . Most of the asymmetry takes place directly after the shock. On the first day after the shock, for 228 out of 1,616 gasoline stations (14\%) a positive shock has a significantly larger impact on the retail price than a negative shock. This number decreases over time. After a week the difference is positive and significant for only 77 stations.

Figure A3 reports the size of the asymmetric effect. For each day I calculate the average difference in the cumulative retail price adjustments for the $22 \%$ of the gasoline stations that price asymmetrically. The average difference is 0.205 cent directly after the shock, but declines over time. Figure A3 also contains the daily average difference over all gasoline stations. It differs substantially from the mean of stations that adjust prices asymmetrically. On day 1 the mean difference over all stations equals 0.046 cent (close to the value from the pooled estimation). After day 1, it decreases rapidly toward zero. On day 1 , the estimated extent of the asymmetry is 0.159 cent (348\%) larger if I only consider stations that adjust prices asymmetrically. 
Figure A2 The days on which the transmission processes after a change in the suggested price are asymmetric (the number of stations that respond asymmetrically per day)

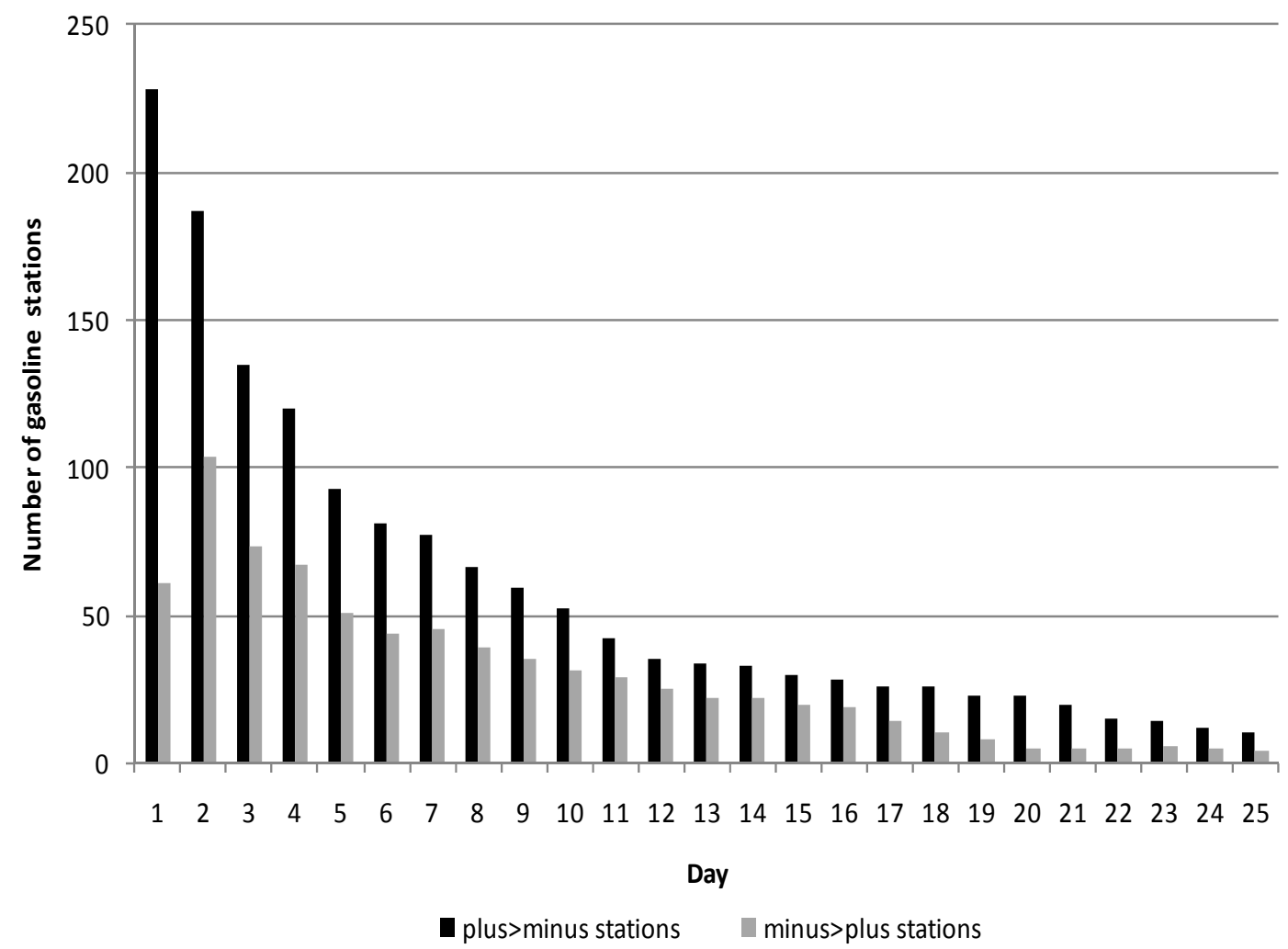

Figure A3 Average extent of asymmetry after a change in the suggested price (difference between the cumulative adjustments)

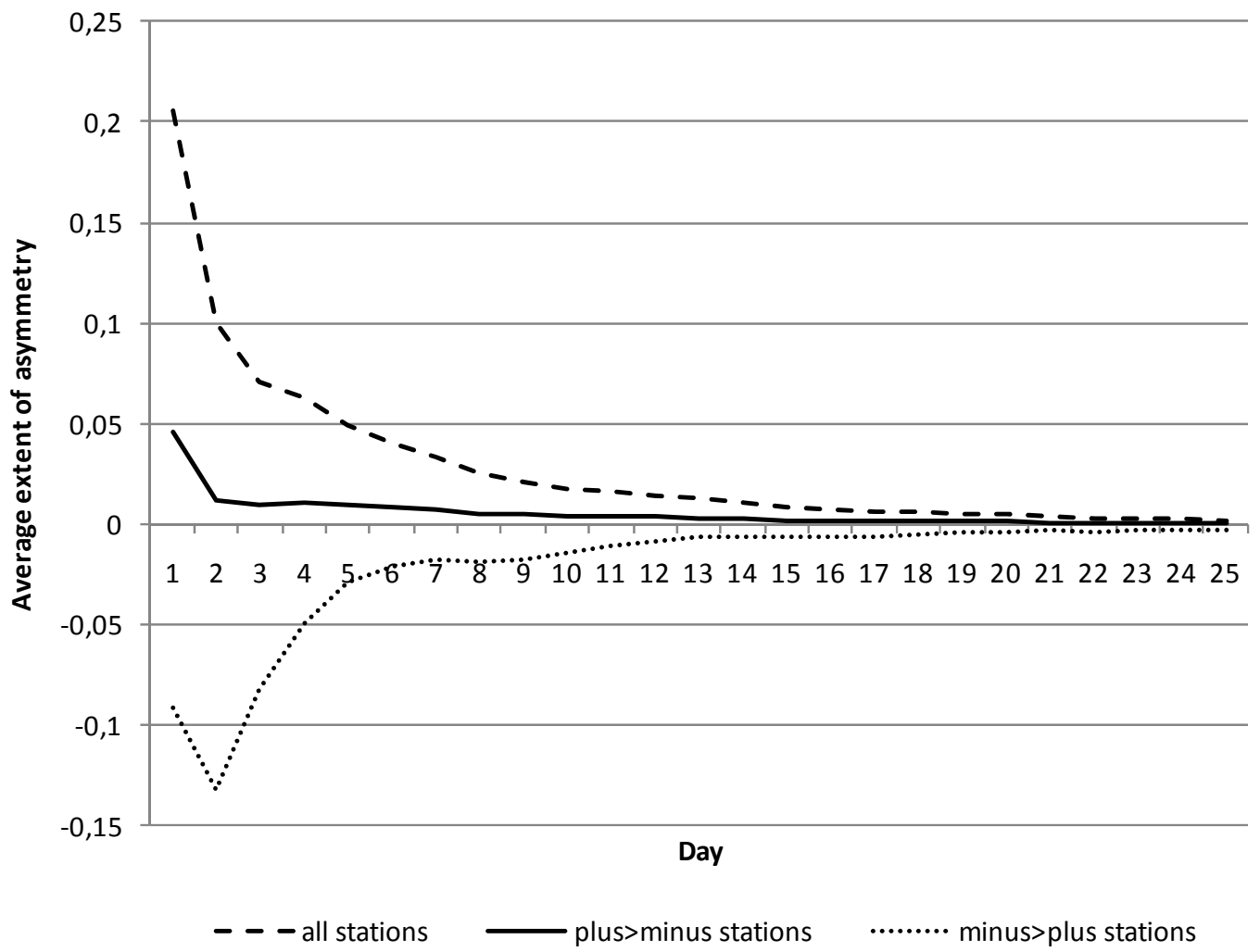


Figure A4 shows the length of the transmission process after a positive shock. The process takes after a positive shock on average 6.1 days for asymmetrically pricing stations and 5.1 days for other stations. I calculate the length of the transmission process after a negative shock as well. For asymmetrically pricing stations the transmission process is faster after a positive shock (on average 2.4 days). For these stations the transmission process of both positive and negative shocks takes longer, but also the difference in length of the two transmission processes is larger. For the other stations the transmission process is on average just a bit faster after a positive shock ( 0.2 days). These results are more in line with expectations than the properties of the estimated transmission processes in Section $4 .^{42}$

Next, I look at gasoline stations that respond faster to decreases than to increases in the suggested price. Table A1 reports the percentage of gasoline stations for which on at least one day the difference between the cumulative price change after a positive shock and the cumulative price change after a negative shock is negative and significantly different from 0 . This is $11 \%{ }^{43}$ For about half of these stations this effects lasts for one day. Figure A2 shows the number of stations for which the difference is negative and significant on each day. On day 2 the difference is significantly negative for 104 gasoline stations. This number declines over time. Figure A3 reports for the $11 \%$ of the stations the size of the average daily difference. The difference between a negative shock and a positive shock is on average 0.092 cent on the first day after the shock, but declines over time.

In Section 4 I found that $38 \%$ of the gasoline stations adjust their prices asymmetrically to changes in the spot market price. In this appendix I find that $22 \%$ of the gasoline stations respond asymmetrically to changes in the suggested price. The latter analysis excludes stations without the brand of one of the five largest oil companies, but this difference does not cause the higher percentage in Section 4. Of the 1,616 stations that I use in this appendix, 39\% respond asymmetrically to changes in the spot market price (and 6\% respond faster to decreases than increases in the spot market price).

\footnotetext{
${ }^{42}$ Like in Section 4, I find that according to the estimations per station the transmission process is on average much shorter than according to the pooled estimation. The maximum length of the transmission process after a positive shock and after a negative shock is according to the pooled estimation 15 days. This maximum is on average 7.2 days according to the estimations per station.

${ }^{43}$ There are 15 stations for which the difference between the cumulative price change after a positive and a negative shock is both significantly positive and significantly negative at least once.
} 
Figure A4 Length of the transmission process after a positive shock in the suggested price

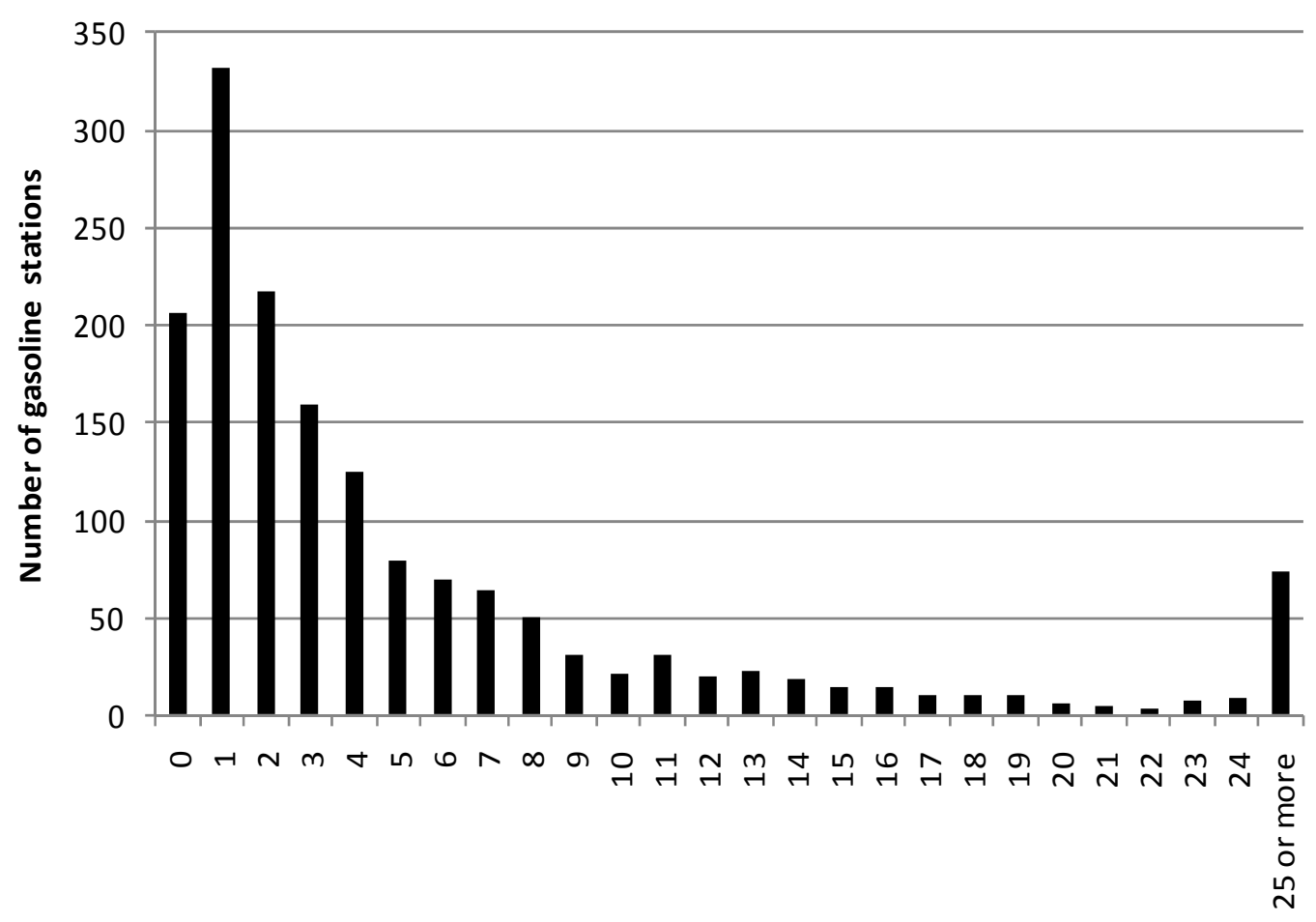

Number of days

As a robustness check for Equation A3, I estimate the same alternative specifications as in Section 4 for all 1,611 stations for which I can estimate all specifications (see Table 2 for the specifications). The percentage of gasoline stations that adjust prices asymmetrically varies between $13 \%$ and $22 \%$. Depending on the specification, the percentage of stations that respond faster to decreases than to increases in the suggested price is between $2 \%$ and $11 \%$. 